\title{
The Lost City hydrothermal system: Constraints imposed by vent fluid chemistry and reaction path models on subseafloor heat and mass transfer processes
}

\author{
W. E. Seyfried, Jr. ${ }^{a}$, Nicholas J. Pester ${ }^{\mathrm{a}, 1}$, Benjamin M. Tutolo ${ }^{\mathrm{a}}$, Kang Ding ${ }^{\mathrm{a}}$ \\ ${ }^{a}$ Department of Earth Sciences, University of Minnesota, Minneapolis, MN, 55455
}

\section{Abstract}

Since the first reported discovery of the Lost City hydrothermal system in 2001, it was recognized that seawater alteration of ultramafic rocks plays a key role in the composition of the coexisting vent fluids. The unusually high $\mathrm{pH}$ and high concentrations of $\mathrm{H}_{2}$ and $\mathrm{CH}_{4}$ provide compelling evidence for this. Here we report the chemistry of hydrothermal fluids sampled from two vent structures (Beehive: 90-116 ${ }^{\circ} \mathrm{C}$, and M6: $\sim 75^{\circ} \mathrm{C}$ ) at Lost City in 2008 during cruise KNOX18RR using ROV Jason 2 and $\mathrm{R} / \mathrm{V}$ Revelle assets. The vent fluid chemistry at both sites reveals considerable overlap in concentrations of dissolved gases $\left(\mathrm{H}_{2}, \mathrm{CH}_{4}\right)$, trace elements $(\mathrm{Cs}, \mathrm{Rb}, \mathrm{Li}, \mathrm{B}$ and $\mathrm{Sr})$, and major elements $\left(\mathrm{SO}_{4}, \mathrm{Ca}, \mathrm{K}, \mathrm{Na}\right.$, $\mathrm{Cl}$ ), including a surprising decrease in dissolved $\mathrm{Cl}$, suggesting a common source fluid is feeding both sites. The absence of $\mathrm{Mg}$ and relatively high concentrations of $\mathrm{Ca}$ and sulfate suggest solubility control by serpentine-diopside-anhydrite, while trace alkali concentrations, especially $\mathrm{Rb}$ and $\mathrm{Cs}$, are high, assuming a depleted mantle protolith. In both cases, but especially for Beehive vent fluid, the silica concentrations are well in excess of those expected for peridotite alteration and the coexistence of serpentine-brucite at all reasonable temperatures. However, both the measured $\mathrm{pH}$ and silica values are in better agreement with serpentine-diopside-tremolite-equilibria. Geochemical modeling demonstrates that reaction of plagioclase with serpentinized peridotite can shift the chemical system away from brucite and into the tremolite stability field. This is consistent with the complex intermingling of peridotite and gabbroic bodies commonly observed within the Atlantis Massif. We speculate the existence of such plagioclase bearing peridotite may also account for the highly enriched trace alkali $(\mathrm{Cs}, \mathrm{Rb})$ concentrations in the

\footnotetext{
${ }^{1}$ Present address: Earth Sciences Division, Lawrence Berkeley National Laboratory, Berkeley, California 94720, USA; E-mail: NJPester@lbl.gov.
} 
28 Lost City vent fluids. Additionally, reactive transport modeling taking explicit account of temperature

29 dependent rates of mineral dissolution and precipitation clarifies the feedback between permeability, heat

30 loss, and changes in the dissolved Si of the vent fluids. Assuming both the Beehive and M6 vent fluids

31 were sourced at similar subseafloor conditions (tremolite buffered at $200{ }^{\circ} \mathrm{C}$ ), model results indicate loss

32 of approximately $30 \%$ Si upon cooling to $\sim 150{ }^{\circ} \mathrm{C}$ during upflow. However, Si concentrations remained

33 largely conservative with continued cooling to lower temperatures owing to unfavorable reaction kinetics.

34 While consistent with the Beehive endmember composition, these results fail to explain the relative $\mathrm{Si}$

35 depletion in the lower temperature M6 fluids. Thus, it may be that more robust kinetic models for silicates

36 are needed to accurately account for the mechanism and rate of silica removal in the unusually high $\mathrm{pH}$ of

37 the Lost City vent fluids. 


\section{INTRODUCTION}

The Lost City hydrothermal field (LCHF) $\left(30^{\circ} 07^{\prime} \mathrm{N}, 42^{\circ} 07^{\prime} \mathrm{W}\right)$ is hosted in ultramafic rocks exposed along the southern face of the Atlantis Massif, which is offset $\sim 15 \mathrm{~km}$ from the Mid-Atlantic Ridge (Blackman et al., 2002; Blackman et al., 2014; Früh-Green et al., 2003; Karson et al., 2006; Kelley et al., 2001; Kelley et al., 2005; Proskurowski et al., 2008). Carbonate-brucite chimneys within the hydrothermal field rise up to $60 \mathrm{~m}$ above the faulted structural ledges upon which they are perched (Kelley et al., 2001; Kelley et al., 2005), providing evidence of permeable conduits for discharge of hydrothermal fluids sourced beneath the seafloor (Ludwig et al., 2006). The hydrothermal fluid that flows from the chimneys is noteworthy in its high $\mathrm{pH}$ and $\mathrm{H}_{2}$ concentrations, as well as abundant and diverse concentrations of dissolved organic compounds, especially methane and organic acids (Kelley et al., 2005; Konn et al., 2009; Lang et al., 2010; Lang et al., 2012; Ludwig et al., 2006; Proskurowski et al., 2008; Proskurowski et al., 2006). These characteristics of the hydrothermal fluid chemistry strongly implicate peridotite alteration, serpentinization, and in the case of the organics, Fischer Tropsch Type (FTT) synthesis (Allen and Seyfried, 2004; Foustoukos et al., 2008; Kelley et al., 2001; Konn et al., 2009; Lang et al., 2010; Ludwig et al., 2006; Proskurowski et al., 2008; Proskurowski et al., 2006; Seewald et al., 2006). The role of peridotite and associated ultramafic rocks in the chemical evolution of Lost City vent fluids is further strengthened by the recovery of serpentinites, partially altered peridotite, and olivinerich gabbro from the southern Atlantis Massif by DSRV Alvin during both reconnaissance and targeted studies in 2001 and 2003 (Boschi et al., 2008; Früh-Green et al., 2003; Kelley et al., 2001; Kelley et al., 2005; Schroeder et al., 2002). The absence of brucite and relative abundance of pyrite in the recovered alteration assemblages, however, are important observations, suggesting more complex geochemical processes than simple peridotite hydrolysis and redox disequilibrium, respectively, if these mineral associations can be directly linked to the chemistry of the Lost City vent fluids (Boschi et al., 2008; Boschi et al., 2006; Delacour et al., 2008b; Früh-Green et al., 2003). Results from the Integrated Drilling Program at Site U1309 (immediately north of the LCHF) show that the central dome is mainly composed 
of gabbroic rocks with minor peridotite (Blackman et al., 2006; Blackman et al., 2014; Delacour et al., 2008a). Mineral assemblages in the core record a complex alteration history that is largely dominated by greenschist facies conditions, providing additional insight on sources of heat and mass transfer reactions in the subseafloor, with implications for the temporal evolution of LCHF (Allen and Seyfried, 2004; Früh-Green et al., 2003). Thus, based on these and similar investigations, it is now clear that Lost City reveals an important type of hydrothermal activity, one that is dominated by alteration of mantle peridotite, and perhaps gabbro, at moderately low fluid temperatures, although higher temperatures in the subsurface and in the geological past cannot be ruled out (Allen and Seyfried, 2004; Blackman et al., 2002; Boschi et al., 2006; Foustoukos et al., 2008; Früh-Green et al., 2003; Karson et al., 2006; McCaig et al., 2007; McCaig et al., 2010; Proskurowski et al., 2008; Schroeder et al., 2002).

There has been great progress made in understanding the effect of temperature and composition on mass transfer processes that could result in the formation of Lost City hydrothermal fluid, although the qualitative and quantitative controls on phase equilibria remain uncertain. For example, in the absence of data for dissolved silica, it is not possible to constrain unambiguously peridotite alteration reactions buffering the $\mathrm{pH}$ of Lost City hydrothermal fluids. Similarly, data on trace alkali concentrations are also unavailable. This limits our ability to infer the source or composition of the (unaltered) protolith, with implications for the fluid/rock mass ratio attending hydrothermal alteration. Although the fluid/rock mass

81 ratio can be estimated using strontium and oxygen isotopes in the vent fluids (Boschi et al., 2008;

82 Foustoukos et al., 2008), other dissolved components provide additional information with which the 83 datasets can be compared, enhancing broader applications. Here we report the concentrations of dissolved 84 species for selected vents in the Lost City hydrothermal system. These data not only augment existing 85 datasets, but can also be used to inform coupled heat and reactive mass transport models, providing 86 information critical to understanding the dynamic feedback between mineral alteration, temperature, 87 permeability, and changes in fluid chemistry between the subsurface and vent sites for this important type 88 of marine hydrothermal system. 


\section{GEOLOGIC SETTING}

The Lost City hydrothermal field is located at a water depth of approximately $750-850$ meters on the southern wall of the Atlantis Massif, approximately $15 \mathrm{~km}$ west of the Mid-Atlantic Ridge (Kelley et al., 2001; Kelley et al., 2005). On the basis of magnetic data, the massif has been undergoing uplift for the past 1.5 m.y., motion that is consistent with the existence of well-developed surficial corrugations (Blackman et al., 2002).

Lost City is located near the central summit of the massif, in close association with normal faults that produce a series of bench-like structures (Fig. 1). These faults provide pathways for circulation and venting of hydrothermal fluid (Kelley et al., 2001; Kelley et al., 2005; Ludwig et al., 2006). On the seafloor, mixing of high $\mathrm{pH}$ and Ca-rich hydrothermal fluid with seawater results in precipitation of variable mixtures of aragonite and brucite. During aging of the chimneys, aragonite is replaced by calcite, while at the same time brucite is rendered unstable in seawater-type fluids and ultimately dissolves (Ludwig et al., 2006). The deposits range from tall pinnacles to flanges and delicate precipitates that grow outward from fissures in the bedrock (Allen and Seyfried, 2004; Kelley et al., 2001; Kelley et al., 2005; Ludwig et al., 2006; Ludwig et al., 2011). Radiometric dating suggests hydrothermal activity at Lost City has been on-going for at least 30-35 kyr (Früh-Green et al., 2003), and perhaps as long as $120 \mathrm{kyr}$ (Ludwig et al., 2011).

Observed sites of venting at Lost City occur largely within a region of approximately $\sim 500 \mathrm{~m}^{2}$. This hydrothermally active area constitutes the core of the field. These and numerous other vents and seeps are generally associated with the intersection of two major faults, one striking east-west, while the other strikes $\sim 020^{\circ}$ (Karson et al., 2006; Kelley et al., 2005; Ludwig et al., 2011). Previous studies have explored in detail the vent locations in the context of structural and tectonic controls, which, in part, resulted in the high resolution bathymetric map shown here (Fig. 1) (Blackman et al., 2002; Karson et al., 2006; Kelley et al., 2001; Kelley et al., 2005; Ludwig et al., 2006; Proskurowski et al., 2008). In 2008 our program focused on two vent structures: the Beehive (BH) and Marker \#6 (M6). Fluid was venting 
114 vigorously at the Beehive, having exit temperatures ranging from $91-116^{\circ} \mathrm{C}$. Lower temperatures $(53-$

$11578^{\circ} \mathrm{C}$ ) were measured at M6 (E-NE of BH, Fig. 1b), where hydrothermal fluid was escaping more 116 diffusively.

\section{3. SAMPLE COLLECTION AND ANALYSIS OF HYDROTHERMAL FLUIDS}

Hydrothermal fluids sampled from the carbonate-brucite structures at Lost City during cruise KNOX18RR were collected by ROV Jason-2 using two types of pressurized, piston driven sampling devices (denoted IGT or CGT) constructed entirely of titanium. These devices, similar in design, use a back pressure of compressed nitrogen to maintain each sample at seafloor pressure during both acquisition and ship-board processing, allowing continuous sub-sampling without degassing any fluid remaining in the sampler. The IGT (isobaric, gas-tight) samplers (Seewald et al., 2002) operate remotely

124 using computer controlled software and ICL (inductively coupled link) hardware that permits non-contact 125 serial communication (Bradley et al., 1995; Fornari et al., 1997) with a mechanical valve that serves as a 126 fluid inlet to the sampler (Fig. 2). Accordingly, opening and closing the valve for timed cycles is

127 possible, thereby assuring complete filling of the $150 \mathrm{ml}$ sampler. The other sampler utilized (Wu et al., 128 2011)(CGT) has a lower volume ( 120 ml), while the valve is opened and closed via action of the 129 submersible manipulator arm in a manner similar to the "majors sampler" (Von Damm et al., 1985), 130 which has long been used during submersible studies of deep sea vents. For both samplers, however, the 131 inherent capability of ICL communication permits monitoring of fluid temperature as the sampler is being 132 filled.

The vent sampling strategy deployed was not to sample the numerous individual vent structures 134 throughout the Lost City hydrothermal field, but rather to focus on just two, as described above. The 135 reason for this involved broader aspects of the dive plan, which required deployment of in-situ chemical 136 sensors at selected vent sites. To verify the chemical sensor data, it was necessary to re-visit and re137 sample the vent fluids over the 4 days during which the ship (R/V Roger Revelle) and ROV (Jason 2) 
were at the Lost City site. Seven samples of the Beehive vent fluid were obtained, while three fluid

139 samples were obtained at Marker \#6. The repeated measurements at both vent sites occurred on separate

140 dives at different times, and with different samplers. This is useful, in that it provides a more complete

141 measure of sampling related variability that can contribute to the reported concentrations of hydrothermal

142 fluid chemistry. Ambient bottom seawater was also collected at Lost City in 2008 to facilitate more

143 accurate endmember extrapolations (section 4.1).

144 On-board processing of fluid samples typically occurred within hours of recovery, with priority

145 given to the most labile components. In general, sub-samples were immediately taken for determination

146 of $\mathrm{pH}$ and dissolved gases (e.g., $\mathrm{H}_{2}, \mathrm{H}_{2} \mathrm{~S}$, and $\mathrm{CH}_{4}$ ). These samples were drawn into glass, gas-tight

147 syringes adapted with PEEK valves that effectively preclude gas loss during subsequent sample handling.

148 Repeated $\mathrm{pH}$ measurements ( \pm 0.05 units) were made with a Thermo-Ross ${ }^{\mathrm{TM}}$ glass electrode, which was

149 standardized daily before each sampling session. Total dissolved sulfide was determined by injection of 1

150 to $3 \mathrm{ml}$ aliquots into a high $\mathrm{pH}$ antioxidant buffer solution (SAOB, Fisher Scientific) that was

151 subsequently titrated with a standardized $\mathrm{Pb}\left(\mathrm{NO}_{3}\right)_{2}$ solution using a sulfide specific $\left(\mathrm{Ag}^{+} / \mathrm{S}^{-2}\right)$ electrode.

152 The low concentrations observed, however, limited resolution using this approach (Table 1). Accordingly,

153 we report dissolved sulfide concentrations only for samples with which there existed reasonable

154 consistency between replicate measurements ( $<10 \% \mathrm{RSD}, 2 \sigma)$. Dissolved $\mathrm{H}_{2}$ and $\mathrm{CH}_{4}$ were analyzed

155 after head space extraction using a gas chromatograph equipped with a molecular sieve column and

156 sequential thermal conductivity and flame ionization detectors. Replicate measurements and

157 standardization protocols suggest an analytical precision in reported values of these gases of $\pm 5 \%(2 \sigma)$.

158 Sub-samples of vent fluid were preserved for shore based analysis at the University of Minnesota.

159 Chlorinity $(\mathrm{Cl}+\mathrm{Br})$ was determined by electrochemical titration using a standardized $\mathrm{AgNO}_{3}$ solution .

160 Based on replicate measurements of seawater standards (IAPSO) and standard-sample-blank protocol, an

161 analytical precision of $\pm 0.5 \%(2 \sigma)$ is indicated. Additional anions $\left(\mathrm{SO}_{4}, \mathrm{Br}\right)$, major cations $(\mathrm{Na}, \mathrm{K}, \mathrm{Ca}$,

$162 \mathrm{Mg}$ ), and minor/trace components ( $\mathrm{Li}, \mathrm{Rb}, \mathrm{Cs}, \mathrm{Sr}, \mathrm{Si}, \mathrm{B}, \mathrm{Fe}$ ) were analyzed by a combination of ion 
chromatography (IC), inductively coupled plasma optical emission spectrometry (ICP-OES), and

164 inductively coupled plasma mass spectrometry (ICP-MS). The analytical uncertainty that attends these

165 measurements is on the order of $2-10 \%(2 \sigma)$ of the reported concentrations, with lower concentration

166 components carrying the greater uncertainty (Pester et al., 2011; Seyfried et al., 2011; Seyfried et al.,

167 2003). These analyses were also calibrated against IAPSO seawater for appropriate elements; and

168 overlapping measurements of major cations by both IC and ICP-OES showed excellent agreement. The

169 analytical uncertainty for $\mathrm{Cs}$ and $\mathrm{Fe}$, however, was much higher, up to 30 and $40 \%$, respectively. In the

170 case of Cs, this is caused by the inherently low concentration and associated analytical challenges. Cs,

171 however, inversely correlates with $\mathrm{Mg}$, as predicted, underscoring the meaningfulness of the data. $\mathrm{Fe}$, on

172 the other hand, has a higher concentration, but fails to correlate with Mg. Moreover, the Fe data represent 173 a composite of the dissolved fraction and the particulate fraction recovered by filtration $(0.45 \mu$ nylon $)$ of

174 the residual fluid in the Ti-samplers. Considering the relatively low total Fe concentration it would take

175 very little "contaminant" Fe (Fe particles unrelated to the intrinsic composition of the Lost City vent 176 fluid) to cause the scatter in the Fe-Mg data, as observed. Thus, although we provide these data, in the

177 absence of a clear Fe-Mg correlation, the data should be considered uncertain. While within analytical

178 error of chlorinity (by titration), reported $\mathrm{Cl}$ concentrations nonetheless reflect subtraction of associated

$179 \mathrm{Br}$ as determined by IC. The fluid chemistry of the Lost City vent fluids sampled during cruise

180 KNOX18RR and analyzed as described above is reported in Tables 1 and 2.

\section{4. RESULTS AND DISCUSSION}

\subsection{The Lost City Hydrothermal Fluid Endmember}

End member concentrations of LCHF vent fluids were calculated by linear regression of seawater

184 and sample compositions to zero Mg (e.g., Von Damm et al. (1985)). Our use of isobaric gas-tight

185 samplers (Seewald et al., 2002; Wu et al., 2011), however, effectively minimized seawater mixing as

186 indicated by the relatively low Mg concentrations in the vent fluids sampled from LCHF in 2008 (Table 

can only occur if the thermocouple and sample inlet tube became decoupled during sampling.

189 Accordingly, this is clearly a failed vent fluid sample, but one that is still useful in that it provides us with 190 another sample of seawater at LCHF with which the hydrothermal vent fluids can be compared. Although 191 the sampled vents were located within relatively close proximity to one another ( 20 m, Fig. 1b), it is still

192 interesting that these fluids reveal such similar chemistry, especially considering clear differences in

193 temperature and fluid flow rate. In general, the overall compositional similarity of the vent fluids reported

194 here is largely in keeping with observations made by previous workers studying related aspects of the

195 LCHF (Kelley et al., 2001; Kelley et al., 2005; Lang et al., 2013; Lang et al., 2012; Proskurowski et al.,

196 2008; Proskurowski et al., 2006). This is particularly true for relatively high-temperature vent fluids and

197 for components affected less by microbial utilization (Lang et al., 2012). Thus, it can be argued that a

198 source fluid common to these two vents, and perhaps others, ascends from a region in the subseafloor 199 undergoing active serpentinization at a common temperature and pressure. This fluid is then dispersed, 200 conductively cooling to variable extents in response to local controls on permeability.

\section{$201 \quad 4.1 .1$ Anions}

The dissolved concentration of endmember sulfate in hydrothermal fluid from the two sites sampled in 2008 is approximately $3.3 \mathrm{mmol} / \mathrm{kg}$ (Fig. 3a; Tables 1 and 2). These data are broadly

204 analogous to values reported earlier for LCHF vent fluids, especially for similarly located vents (Kelley et 205 al., 2005; Lang et al., 2012). Overall, endmember sulfate concentrations throughout the entire Lost City 206 vent field have been reported to range from approximately 1 to $4 \mathrm{mmol} / \mathrm{kg}$ (Kelley et al., 2005; Lang et 207 al., 2012). These earlier studies have also demonstrated that the vent fluids with the highest sulfate 208 concentrations tend to have relatively low total dissolved sulfide concentrations $(\sim 0.25 \mathrm{mmol} / \mathrm{kg})(\mathrm{Kelley}$ 209 et al., 2005; Lang et al., 2012), and might better represent the inventory of dissolved sulfur species 210 intrinsic to the source fluid feeding LCHF (Lang et al., 2012). In contrast, the low sulfate and high sulfide 211 vent fluids (not sampled during the present study) appear to be affected by microbially mediated sulfate 
212 reduction (Lang et al., 2012). This is consistent with the moderately low temperature of these fluids, the

$213 \delta^{34} \mathrm{~S}$ sulfate values in excess of $+30 \%$ (Vienna Canyon Diablo troilite) (Kelley et al., 2005), and biomass

214 abundance and carbon isotopic composition (Lang et al., 2012).

215 Considering the well-known hydration effects that accompany serpentinization of peridotite

216 (Frost and Beard, 2007; Früh-Green et al., 2004; Sanford, 1981), dissolved chloride concentrations in

217 Lost City vent fluids might be expected to exceed seawater values. Previously reported values, however,

218 are similar to seawater (Kelley et al., 2001). The chloride endmember of fluids sampled during the present

219 investigation again demonstrate near seawater concentrations, but a statistically significant negative

220 correlation with $\mathrm{Mg}$ is apparent (Fig. 3b). Indeed, the endmember $\mathrm{Cl}$ concentrations in fluids from both

$221 \mathrm{BH}$ and M6 are approximately 10-15 mmol/kg below that of bottom seawater at Lost City (Table 1, 2;

222 Fig. 3b). One well known mechanism to account for this involves chloride uptake by serpentine (Mevel,

223 2003; Sharp and Barnes, 2004). Serpentinized peridotite from submarine and even subareal settings often

224 shows chloride enrichment. In this case the enrichment can occur either as water soluble phase within

225 serpentine, or by isomorphic substitution of $\mathrm{Cl}$ for $\mathrm{OH}$, potentially resulting in formation of an iowaite

226 component in the serpentine structure. Sharp and Barnes (2004) determined the existence of nearly

227 equivalent amounts of water and non-water soluble $\mathrm{Cl}$ in serpentinites from ODP cores, totaling

228 approximately $0.5 \% \mathrm{Cl}$. At a fluid/rock mass ratio of approximately 2-4 (Foustoukos et al., 2008), a value

229 of approximately $0.07-0.14 \% \mathrm{Cl}$ can be estimated for the coexisting serpentine if the compositional

230 change in the vent fluid and serpentine can be directly linked in time and space. This is a generous

231 assumption considering the complex tectonic and hydrothermal history at the southern wall of the Atlantis

232 Massif and the associated Lost City hydrothermal field (Boschi et al., 2008; Boschi et al., 2006). In

233 contrast to $\mathrm{Cl}$ uptake by serpentine minerals, it is also possible that the slight decrease in $\mathrm{Cl}$ observed in

234 the Lost City vent fluids occurs indirectly in association with dehydration of minerals, such as brucite.

235 The lack of brucite associated with serpentinites recovered from the southern wall of the Atlantis Massif

236 is well known (Boschi et al., 2008), and may provide a mechanism by which water is remobilized, 

during hydrothermal alteration of Al-bearing peridotite can be expected to render brucite unstable,

239 enhancing serpentine formation, while releasing water. An analogous process involving serpentine

240 dehydration to talc to account for the change in concentration and isotopic composition of boron

241 associated with the Atlantis Massif detachment fault and oceanic core complex has been emphasized by

242 Boschi et al. (2006). Thus, both direct ( $\mathrm{Cl}$ metasomatism) and indirect (dehydration reactions)

243 mechanisms can account for the slight but significant decrease in $\mathrm{Cl}$ that we have observed in Lost City

244 vent fluids. Either scenario is unavoidably complicated in space and time, potentially involving a change

245 in the physicochemical environment governing fluid-mineral exchange. Although the mechanism is not

246 entirely clear, such $\mathrm{Cl}$ depletion is important in that it provides a previously unrecognized clue that can be 247 used with other data to decipher the chemical and mineralogical evolution of the Lost City hydrothermal 248 system.

Relative to the high precision of the chlorinity titration, dissolved $\mathrm{Br}$ analysis by IC carries a more modest precision $(\sim 3 \%, 2 \sigma)$; and nearly all $\mathrm{Br}$ concentrations, as well as the associated $\mathrm{Br} / \mathrm{Cl}$ ratios, 251 fall within error of seawater (Tables 1 and 2).

\subsubsection{Major cations}

Dissolved concentrations of the major alkali elements, $\mathrm{Na}$ and $\mathrm{K}$, in Lost City vent fluids are in

254 excess of ambient seawater values (Table 1, 2, Fig. 4). The observed increase in the concentration of $\mathrm{Na}$ 255 is particularly interesting in light of the previously discussed decrease in dissolved $\mathrm{Cl}$, enhancing further 256 the $\mathrm{Na}$ addition to solution when normalized to $\mathrm{Cl}$, as is typically done for hydrothermal vent fluids

257 (Pester et al., 2012; Von Damm, 2000). Sodium is likely derived from dissolution of a Na component in 258 pyroxene or plagioclase during fluid-rock interaction at depth. Results of peridotite-seawater experiments 259 conducted previously at a range of temperatures often reveal the release of $\mathrm{Na}$ to the fluid, likely in 260 exchange for seawater Ca or Mg (Allen and Seyfried, 2003; Seyfried et al., 2007). Although it is often 261 difficult to quantify the magnitude of Na release from unstable silicate minerals in seawater in light of on- 
going hydration effects, Seyfried et al. (2007) showed this clearly by linking the increase in dissolved Na to corresponding changes in $\mathrm{pH}$. Potassium, in contrast, has long been recognized as a so-called "soluble

264 element" in both mafic and ultramafic chemical systems, although the extent to which it partitions into the 265 fluid is considerably better established for basalt than for more ultramafic lithologies. That the Lost City 266 vent fluids reveal such a small increase in potassium concentration relative to seawater (within analytical 267 error) provides qualitative evidence of a relatively high fluid/rock mass ratio attending subseafloor 268 exchange reactions, and/or an appreciably low K concentration in the protolith.

270 4b). In general, the data reported here are consistent with analogous data reported earlier by Kelley et al.

271 (2001). Owing to the relative abundance of clinopyroxene (Cpx) in mantle peridotite, $\mathrm{Mg}$ (seawater 272 derived) for $\mathrm{Ca}$ (rock derived) exchange accounts best for the observed increases in dissolved $\mathrm{Ca}$, as 273 follows:

$$
\text { Diopside }+\mathrm{Mg}^{++}+1.333 \mathrm{H}_{2} \mathrm{O}=0.667 \text { Chrysotile }+\mathrm{Ca}^{++}+0.667 \mathrm{SiO}_{2(\mathrm{aq})}
$$

275 The dissolved silica produced can be expected to be controlled by coexisting alteration reactions involving these and other silicate minerals. Numerous experimental and theoretical peridotite alteration 277 studies at a range of temperatures and pressures support variants of reaction (1) (Allen and Seyfried, 278 2003, 2005; Berndt et al., 1988; Janecky and Seyfried, 1986; Klein et al., 2013; Seyfried et al., 2007). 279 Because of chemical and physical conditions intrinsic to the Lost City hydrothermal system it can be 280 inferred that diopside, tremolite, anhydrite, and perhaps even plagioclase (see below) can affect Ca 281 solubility, each mineral precipitating and/or dissolving with reaction progress between seawater derived 282 aqueous fluid and a largely ultramafic protolith. We cannot, however, rule out reactions involving a wide 283 range of other Ca-bearing primary and secondary mineral that may also play a role at some stage in the 284 chemical evolution of dissolved Ca in Lost City vent fluids (Beard and Hopkinson, 2000; Klein et al., 285 2013). 


\subsubsection{Trace elements}

Trace alkali elements in basalt hosted hydrothermal systems have long been recognized for their lack of solubility control, especially at elevated temperatures (Berndt and Seyfried, 1990; Pester et al., 2008; Seyfried et al., 1984). At Lost City these elements show clear enrichment relative to seawater, though the magnitude differs for each element (Fig. 5a-c). As with many other components measured in the Lost City vent fluids, no significant differences can be discerned for the trace alkali elements between

292 the BH and M6 in keeping with a common source. This is also true of dissolved Sr, which shows slight 293 increases relative to seawater (Fig. 5d), consistent with data previously reported by Ludwig et al. (2006) 294 in connection with their study of the chemical and mineralogical evolution of the carbonate chimneys at 295 Lost City. Importantly, Foustoukos et al. (2008) combined the Sr concentration and isotope data with the 296 reaction path model of Berndt et al. (1988) to calculate a fluid/rock mass ratio of 2-4 for the Lost city 297 hydrothermal system. If the trace alkali elements in the Lost City vent fluids are extracted quantitatively 298 from a depleted mantle source (Salters and Stracke, 2004), fluid/rock mass ratios of approximately 5, 0.6, and 0.9 can be estimated from the observed enrichments (relative to seawater) of $\mathrm{Li}, \mathrm{Cs}$ and $\mathrm{Rb}$, respectively. An extraction efficiency of less than $100 \%$, however, would result in lower values, as is

301 typically the case for Li. For example, both basalt alteration experiments and data from exposed dikes at 302 Hess Deep exhibit only 50 - 70\% Li removal from the rock (Brant et al., 2012; James et al., 2003;

303 Seewald and Seyfried, 1990; Seyfried et al., 1984). Assuming similar Li solubility constraints for Lost 304 City, associated fluid/rock ratios are lower (2.5 - 3.5), and therefore consistent with the range of values 305 predicted by Sr isotopes. While their extraction efficiencies are indeed higher than that of Li, the low 306 fluid/rock ratios estimated using $\mathrm{Cs}$ and $\mathrm{Rb}$ still contrast sharply with those predicted by both $\mathrm{Li}$ and $\mathrm{Sr}$.

307 One interpretation is that there exists sources of $\mathrm{Cs}$ and $\mathrm{Rb}$ in amounts greater than typical of depleted 308 mantle. For example, basalts from the nearby Lucky Strike seamount $\left(37^{\circ} \mathrm{N}\right)$ exhibit typical (MORB) 309 bulk Li concentrations, yet they are highly enriched in $\mathrm{Rb}$ and $\mathrm{Cs}$, having average $\mathrm{Rb} / \mathrm{Li}$ and $\mathrm{Cs} / \mathrm{Li}$ ratios 310 approximately 10 times higher ( $\max \sim 20 \mathrm{x})$ than normally observed (Pester et al., 2012). Though we do 
311 not suggest any connection with the Lucky Strike regime, these data nonetheless demonstrate the

312 existence of a protolith uniquely enriched to a degree that can possibly explain the trace alkali ratios in

313 Lost City vent fluids.

314 Although there are uncertainties with estimating the relative mobility of trace elements,

315 especially when dealing with an inferred composition of mantle rocks, reliance on constraints imposed by

316 the actual endmember concentrations of mobile elements and isotopes of elements ( $\mathrm{Sr}$ ) in Lost City vent

317 fluid is advantageous in this regard. Estimates of fluid/rock mass ratio based on the chemical and/or

318 isotopic composition of rock samples obtained by dredging are similarly useful, but measure the end-

319 product or integrated effects of potentially long-lived hydrothermal activity that could vary in space and

320 time. The integrated fluid/rock ratios based on $\mathrm{Sr}$ and $\mathrm{Nd}$ isotopes measured for rocks recovered from the

321 southern Atlantis Massif, for example, are substantially higher than those based on geochemical data from

322 the active (present-day) stage of metamorphism resulting in Lost City vent fluid chemistry (Boschi et al.,

323 2008; Boschi et al., 2006; Delacour et al., 2008b). Thus, the very different conclusions reached in terms

324 of alteration temperature and/or fluid/rock mass ratio based on the two different perspectives (altered rock

325 or fluid composition) are not altogether surprising.

326 Boron in Lost City vent fluids is well below seawater values with the two vent sites virtually

327 indistinguishable with respect to their endmember concentrations (Fig. 6). This is consistent with

328 previously reported data (Boschi et al., 2008; Foustoukos et al., 2008; Kelley et al., 2001; Kelley et al.,

329 2005). This is also consistent with results of experimental peridotite alteration studies at a wide range of

330 temperatures and pressures, which have long confirmed B solubility limits in fluids coexisting with

331 hydrous magnesium silicates, such as serpentine (Janecky and Seyfried, 1986; Seyfried and Dibble, 1980;

332 Seyfried et al., 2007). The relatively high $\mathrm{pH}$ that attends peridotite alteration by seawater, especially at

333 low to moderate temperatures, likely plays a key role in B uptake by serpentine and coexisting hydrous

334 silicates. That is, $\mathrm{pH}$ governs the coordination chemistry of dissolved boron with the trigonal $\left(\mathrm{B}\left(\mathrm{OH}_{3}\right)\right)$

335 and tetragonal $\left(\mathrm{B}(\mathrm{OH})_{4}^{-}\right)$species dominating at relatively low and high $\mathrm{pH}$, respectively (Palmer et al., 
1992; Palmer et al., 1987; Spivack and Edmond, 1987). Thus, the incorporation of boron in serpentine likely entails borate species replacing silicon in the crystal lattice, as opposed to simple adsorption. Not surprisingly, serpentinized peridotite samples recovered by submersible in the vicinity of the Atlantis

339 Massif are enriched in boron (Boschi et al., 2008). Moreover, boron removal from seawater during

340 serpentinization is positively correlated with $\delta^{11} \mathrm{~B}$, while showing little or no correlation with $\delta^{18} \mathrm{O}$, adding

341 strength to the argument that B uptake is largely controlled by the prevailing $\mathrm{pH}$ conditions in the

342 subseafloor reaction zone at Lost City (Boschi et al., 2008; Foustoukos et al., 2008).

\subsubsection{Dissolved silica}

In contrast with virtually all other elements, dissolved silica in Lost City vent fluids shows a

345 relatively complex range of concentrations, yielding different endmembers for the two sites sampled

346 (Table 1, 2 and Fig. 7). For example, the endmember Si concentration in fluids diffusively venting from

347 the M6 site is similar to background seawater $(\sim 25 \mu \mathrm{mol} / \mathrm{kg})$ in spite of moderately high temperatures

$348 \quad\left(\sim 75-78^{\circ} \mathrm{C}\right)$ and the absence of seawater mixing effects for all but the one failed M6 sample. In sharp

349 contrast with M6, hydrothermal fluid venting more vigorously from the Beehive $(\mathrm{BH})$ structure is

350 characterized by Si concentrations approximately 3 times greater than seawater, with a maximum of 94

$351 \mu \mathrm{mol} / \mathrm{kg}$. Although these Si concentrations might be interpreted as low, especially in comparison with

352 basalt hosted hydrothermal systems (Butterfield et al., 2003; Von Damm, 1995, 2000; Von Damm et al.,

353 1998), higher values should not be expected for fluids coexisting with ultramafic minerals and their

354 hydrous alteration products at low to moderate temperatures (Allen and Seyfried, 2004; Frost and Beard,

355 2007). Furthermore, the data for dissolved Si provide information critical to the accurate interpretation of

356 the chemical evolution of the Lost City vent fluids. The relatively low Si concentrations of fluids venting

357 from M6, for example, may reflect the effect of longer residence times along fluid flow path in the

358 subsurface with the potential for Si removal by re-equilibration processes. That M6 vent fluids are also

359 cooler is consistent with such an interpretation, since the lower temperature could be expected to decrease

360 Si solubility. The higher Si concentrations expressed in BH vent fluid are in keeping with better 
preservation of Si buffering reactions directly associated with the subseafloor source conditions, although, even here, Si loss cannot be ruled out entirely. As emphasized below, the Si concentrations of both vent fluids, but especially BH, are well in excess of those likely if controlled by the coexistence of bruciteserpentine-diopside, an alteration assemblage often associated with serpentinization of mantle peridotite (Frost and Beard, 2007; Janecky and Seyfried, 1986; McCollom and Bach, 2009; Palandri and Reed, 2004; Seyfried et al., 2007; Wetzel and Shock, 2000). Thus, the moderately high dissolved silica in 367 conjunction with trace alkali element concentrations, especially dissolved $\mathrm{Cs}$ and $\mathrm{Rb}$, point to the 368 existence of subseafloor reactions at Lost City considerably more complex than would be suggested by 369 simple olivine hydrolysis.

\subsubsection{Dissolved gases}

One of the more interesting and important aspects of the Lost City hydrothermal system is the 372 high concentrations of dissolved $\mathrm{H}_{2}$ and $\mathrm{CH}_{4}$ in the endmember vent fluids (Bradley et al., 2009; Kelley 373 et al., 2001; Kelley et al., 2005; Lang et al., 2010; Proskurowski et al., 2008; Proskurowski et al., 2004; 374 Proskurowski et al., 2006; Seewald et al., 2006). All of the fluid samples reported here similarly show high $\mathrm{H}_{2}$ and $\mathrm{CH}_{4}$ concentrations, providing additional time series data bearing on the geochemical stability of the hydrothermal system (Table 1, 2, Fig. 8). The high $\mathrm{H}_{2}$ concentrations are almost certainly

377 a result of olivine hydrolysis with $\mathrm{H}_{2}$ buffering likely provided by the coexistence of Fe bearing 378 serpentine and magnetite (Frost and Beard, 2007; Klein et al., 2009; Klein et al., 2013; McCollom and 379 Bach, 2009; Seyfried et al., 2007; Sleep et al., 2004). The noteworthy concentrations of dissolved $\mathrm{CH}_{4}$ 380 might be linked to $\mathrm{H}_{2}$ by abiotic synthesis, but also to microbial metabolism, especially for fluids that 381 vent less vigorously from seeps throughout the vent field (Konn et al., 2009; Lang et al., 2010; Lang et 382 al., 2013; Proskurowski et al., 2006). The focused flow fluids at Lost City, however, provide clearer 383 insight into deeper and higher temperature reactions, and an abiotic origin of methane and other low 384 molecular weight hydrocarbons (Bradley et al., 2009; Lang et al., 2012; Proskurowski et al., 2006). The 385 distinct "inverse" trend in stable carbon and hydrogen isotopic composition of $\mathrm{C}_{1}$ to $\mathrm{C}_{4}$ hydrocarbons is 
consistent with FTT synthesis. Radiocarbon data suggest mantle-derived inorganic carbon is the source of carbon for methane synthesis as opposed to seawater derived bicarbonate (Proskurowski et al., 2006).

\subsection{Geochemical Modeling and Phase Equilibria Constraints at Lost City}

Geochemical modeling of peridotite alteration by seawater and other aqueous fluids has long been used to illustrate the effect of temperature, mineral composition, or fluid/rock mass ratio on the

391 chemical and mineralogical evolution of peridotite, peridotite alteration minerals, and the composition of

392 the coexisting aqueous phase (Allen and Seyfried, 2003; Alt and Shanks, 2003; Foustoukos et al., 2008;

393 Janecky and Seyfried, 1986; Klein et al., 2013; Ludwig et al., 2006; McCollom and Bach, 2009; Palandri

394 and Reed, 2004; Wetzel and Shock, 2000). Results of such simulations have provided critical insight on:

395 (1) The role of temperature and peridotite composition on $\mathrm{H}_{2}$ generation that can be linked to alteration

396 mineral pathways, microbial metabolism, and organic synthesis (Amend et al., 2011; Klein et al., 2013;

397 McCollom and Bach, 2009; Seewald et al., 2006); (2) The effect of mixing between seawater and

398 hydrothermal fluid buffered by peridotite alteration products on the formation and mineralogical

399 evolution of carbonate hosted chimney deposits at Lost City and elsewhere (Allen and Seyfried, 2004;

400 Ludwig et al., 2006; McCollom and Bach, 2009); and (3) The effectiveness of peridotite alteration

401 products (e.g., brucite, serpentine, diopside) in buffering aspects of the fluid chemistry at a range of

402 temperatures and fluid/rock mass ratios applicable to the Lost City hydrothermal system. It is this third

403 point that is of most interest to us here, especially regarding the dissolved silica concentrations.

405 fluids it is necessary to calculate the distribution of aqueous species at conditions applicable to LCHF.

406 The thermodynamic database for aqueous species and minerals used for this was created using the

407 DBCreate software package (Kong et al., 2013). These data are largely consistent with the standard

408 SUPCRT92 dataset (Johnson et al., 1992; Sverjensky et al., 1997; Tutolo et al., 2014), with exceptions

409 outlined in other geochemical modeling studies that take advantage of more recent experimental data

410 (Allen and Seyfried, 2004; Foustoukos et al., 2008; Seyfried et al., 2007; Seyfried et al., 2010; Tutolo et 
411 al., 2014). Ion activities for charged species were calculated using the extended form of the Debye Hückel 412 equation as described by Helgeson (1969) and Helgeson and Kirkham (1974). The activity coefficients

413 for all uncharged species, however, were taken to be unity (Helgeson, 1969; Helgeson et al., 1981; Tutolo 414 et al., 2015). Model calculations were conducted at temperatures less than or equal to $200^{\circ} \mathrm{C}$, largely in 415 keeping with constraints imposed by the mineralogical and isotopic composition of dredged samples at or 416 near the Lost City vent field, as well as the chemical and isotopic composition of the vent fluids.(Allen 417 and Seyfried, 2004; Boschi et al., 2008; Foustoukos et al., 2008; Früh-Green et al., 2003; Proskurowski et 418 al., 2008). All temperatures estimated from chemical and isotopic geothermometers exceed measured exit 419 temperatures of the Lost City vents, which strongly suggests the fluids cool conductively on ascent to the 420 seafloor (Allen and Seyfried, 2004), a characteristic in keeping with most other hydrothermal vent fluids 421 at mid-ocean ridges (Pester et al., 2014; Pester et al., 2012). The subseafloor pressure at Lost City is 422 difficult to constrain owing to fluid circulation pathways made possible by detachment related tectonics. 423 However, the recent observation that fluid circulation is limited below $750 \mathrm{~m}$ within the Atlantis Massif 424 (Blackman et al., 2014) may be used in the absence of other data to constrain total hydrostatic pressure to 425150 bars, as was done here. Nevertheless, at low to moderate temperatures (e.g., $\left.200^{\circ} \mathrm{C}\right)$ variation in 426 pressure will not significantly affect results of phase equilibria calculations (Tutolo et al., 2014). Thus, 427 even somewhat deeper circulation would not cause significant variability in the predicted composition of 428 vent fluid chemistry at Lost City.

429 It is well known that olivine has no field of stability in aqueous fluids at low to moderate 430 temperatures and pressures. Thus, given sufficient time, it will be replaced completely by serpentine 431 (chrysotile) plus brucite, as follows:

$$
\text { Olivine }+1.5 \mathrm{H}_{2} \mathrm{O}=.5 \text { Brucite }+.5 \text { Chrysotile }
$$

433 Taking explicit account of constraints imposed by distribution of aqueous species calculations, the 434 activity of dissolved silica can be calculated as a function of temperature assuming chrysotile-brucite 435 coexistence (Fig. 9). As expected, dissolved silica concentrations are predicted to be extremely low at all 
temperatures, and do not exceed $5 \mu \mathrm{mol} / \mathrm{kg}$, even at $200^{\circ} \mathrm{C}$. Furthermore, silica activity (in reference to

437 Eq. 2) is unaffected by the potential stability of diopside at chemical and physical conditions relevant to

438 the Lost City hydrothermal system (Allen and Seyfried, 2004), although this does affect pH (see below).

439 The maximum silica concentration measured in the Beehive vent fluids, however, precludes definitively

440 the participation of brucite in buffering aqueous silica, favoring instead an alteration assemblage more

441 consistent with tremolite-chrysotile-diopside at approximately $180^{\circ} \mathrm{C}$ (Fig. 9). This temperature is broadly

442 consistent with the predicted range of other chemical and isotopic geothermometers that have been

443 applied to the Lost City vent fluids, including anhydrite-fluid equilibria (Allen and Seyfried, 2004; Lang

444 et al., 2012) and serpentine-fluid oxygen isotope data (Foustoukos et al., 2008). Our more recent data for

445 the Lost City vent fluids, in particular dissolved $\mathrm{Ca}$ and sulfate concentrations, while taking explicit

446 account of recent revisions to thermodynamic data for aqueous species (Tutolo et al., 2014), suggests a

447 temperature of $\sim 180^{\circ} \mathrm{C}$ based on anhydrite-fluid equilibria (Fig. 9). In all cases, however, variation is still

448 likely owing to existing uncertainties in analytical and thermodynamic data used for mineral solubility

449 calculations, as well as the unsettled fractionation factors for oxygen isotope data for the serpentine-fluid

450 system. It is for this reason that $200 \pm 50^{\circ} \mathrm{C}$ is most often expressed for the temperature range of

451 subseafloor reactions that contribute most directly to the formation of the Lost City vent fluid at present

452 (Allen and Seyfried, 2003; Allen and Seyfried, 2004; Boschi et al., 2008; Boschi et al., 2006; Foustoukos

453 et al., 2008).

As noted above, the instability of brucite in the subseafloor reaction zone at Lost City is best illustrated by plotting the Beehive endmember composition within an aqueous activity diagram $\left(200^{\circ} \mathrm{C}\right.$ and 150 bars), taking explicit account of the distribution of species in the $\mathrm{CaO}-\mathrm{MgO}-\mathrm{SiO}_{2}-\mathrm{NaCl}-\mathrm{HCl}-\mathrm{H}_{2} \mathrm{O}$ system. Fig. 10 thus shows $a \mathrm{Ca}^{++} / a^{2} \mathrm{H}^{+}$as a function of dissolved silica $\left(a \mathrm{SiO}_{2}\right.$ (aq) $)$ for these two limiting cases: one where chrysotile and diopside coexist with brucite; and the other, where chrysotile and diopside coexist with tremolite. The difference in $a \mathrm{SiO}_{2(\text { aq) }}$ for these two limiting conditions results in a 460 change of approximately three orders of magnitude in $a \mathrm{Ca}^{++} / a^{2} \mathrm{H}^{+}$, with important implications for $\mathrm{pH}$, at 
both reaction zone conditions and when the fluids cool on ascent to the seafloor. For example, the pH

$462\left(200^{\circ} \mathrm{C}\right)$ of fluid buffered by brucite-chrysotile-diopside and tremolite-chrysotile-diopside is 8.12 and 7.12 respectively. The $25^{\circ} \mathrm{C}$ equivalents of these fluids would also differ by approximately a full $\mathrm{pH}$ unit, such 464 that the brucite bearing system could be expected to achieve measured $\mathrm{pH}$ values as high as $\sim 11.5$, while 465 this would be $\sim 10.5$ for the tremolite bearing system (Fig 11). Foustoukos et al. (2008) performed similar 466 calculations with similar results, but their lack of information about dissolved silica in Lost City vent 467 fluids precluded consideration of a "brucite out" scenario. bottom seawater $(\sim 25 \mu \mathrm{mol} / \mathrm{kg})$, but still in excess of that predicted for serpentine-brucite-diopside equilibria at all applicable temperatures (Fig. 9). If we assume these fluids were at one time also in equilibrium with the tremolite-chrysotile-diopside assemblage at a temperature similar to that indicated by Beehive, then it is clear the M6 vent fluids lost $\mathrm{Si}$ on ascent to the seafloor (see below). One process that might account for the loss of Si from M6 vent fluid could entail serpentinization of brucite in the chimney 474 structure through which these fluids diffusively vent. If such were the case, however, serpentine would be abundantly present in these deposits, and this seems not to be the case (Ludwig et al., 2006), implicating reactions at greater depth beneath the seafloor.

\subsubsection{Compositional controls on hydrothermal alteration reactions at the LCHF}

479 City could be accounted for by interaction of mantle peridotite with fluids rich in silica from previous 480 reaction with gabbro, the abundance of which is well known in and around the south wall of the Atlantis 481 Massif (Boschi et al., 2008; Boschi et al., 2006). Indeed, based on careful studies of hydrothermally 482 altered peridotite and gabbro, these investigators confirmed from major and trace element data that there 483 potentially exists interaction between gabbroic and ultramafic rocks. Thus, a form of silica metasomatism 484 could facilitate the replacement of a brucite bearing alteration assemblage by one containing tremolite. In 485 a somewhat similar way, the composition of the putative peridotite in the subseafloor at Lost City may 
not be typical of mantle rocks, and could contain zones of peridotite into which were intruded mafic melt

487 lenses and/or chemically evolved gabbroic bodies. Abyssal peridotites cut by gabbro, for example, have 488 often been reported in rocks dredged from mid-ocean ridges (Cannat et al., 2010; Cannat et al., 1997b;

489 Constantin, 1999; Miller et al., 2004), with the peridotite and gabbro correspondingly modified in

490 composition to an extent that reflects the chemical and physical conditions of melt/gabbro impregnation

491 of the host peridotite. This same association has also been recognized for peridotite recovered from holes

492 U1309B and U1309D at the Atlantis Massif, here referred to as "plagioclase peridotite" (Tamura et al.,

493 2008). Somewhat similar associations have also been reported for lithologies recovered from the southern

494 wall of the Atlantis Massif (Boschi et al., 2006), indicating that reaction of seawater with plagioclase

495 (gabbro) bearing peridotite could be the key to the elimination of brucite, with silica mobility being an 496 effect, not a cause.

To examine this possibility we conducted a simple reaction model in which unaltered seawater was incrementally added to $1 \mathrm{~kg}$ peridotite of harzburgite composition (Janecky and Seyfried, 1986; McCollom and Bach, 2009) at $200^{\circ} \mathrm{C}$ and 150 bars, while plagioclase (An80) was simultaneously reacted. The GWB software package supported with thermodynamic data for minerals and aqueous species as

501 described previously was used for the simulation (Fig, 12). As expected, the complete lack of stability of

502 olivine and orthopyroxene at the conditions used for the model results in formation of serpentine

503 (chrysotile) and brucite in amounts generally equivalent to the mass of the sum of olivine and

504 orthopyroxene. Clinopyroxene (diopside), is stable throughout the simulation in a manner consistent with 505 previous models of this sort (Allen and Seyfried, 2004; Foustoukos et al., 2008; J $\square$ ns et al., 2010; Klein 506 et al., 2013; McCollom and Bach, 2009; Palandri and Reed, 2004). With the simultaneous addition of 507 plagioclase into the system, however, chlorite forms from serpentine and brucite. When the addition of 508 plagioclase achieves approximately 100 grams, which is roughly equivalent to $10 \%$ of the initial 509 peridotite $(\mathrm{Ol}+\mathrm{OPx}+\mathrm{CPx})$, brucite is eliminated as a component, being replaced by chlorite, anhydrite, 510 and tremolite. Owing to mass balance constraints, $\mathrm{Mg}$-alteration mineral products are dominated by 
511 serpentine, but these also now include approximately $10 \%$ chlorite, and considerably lesser quantities of

512 tremolite and diopside (Fig. 12a). Although tremolite and diopside are relatively minor in overall

513 abundance, their formation is critical to $\mathrm{pH}$ buffering (Figs. 9-11).

514 The elimination of brucite with addition of plagioclase not only permits the formation of

515 tremolite, but also allows silica to increase (Fig. 12b). With the increase in silica, $\mathrm{Mg}$ and $\mathrm{Al}$ are predicted

516 to increase and decrease respectively, although both of these species are maintained by phase equilibria at

517 similarly low concentrations. Owing to analytical/sampling limitations, such minor differences cannot be

518 resolved in the vent fluid chemistry. The model results support the hypothesis that alteration of relatively

519 small amounts of plagioclase which occurs simultaneously with serpentinization of olivine and

520 orthopyroxene can account for the noteworthy concentrations of dissolved silica observed for the Lost

521 City vent fluids by rendering brucite unstable, while Mg-chlorite and tremolite are predicted to form in its

522 place. It is important to emphasize that our simple choice of $\mathrm{An}_{80}$ plagioclase to represent any potential

523 micro and macro-scale melt penetrations into peridotite will necessarily fail to produce the full range of

524 variability observed in natural systems. If the gabbro crystallized from melts that had undergone variable

525 degrees of fractional crystallization, this would then give rise to plagioclase with lower An content, while

526 also being associated with relatively Si-rich pyroxene minerals (Cannat et al., 1997a). Rocks of such

527 enriched composition would have an even greater capacity to eliminate brucite from altered peridotite

528 host rocks during subsequent reaction with aqueous fluids.

529 The relatively high concentrations of trace alkali elements in Lost City vent fluids, especially Cs

530 and $\mathrm{Rb}$, similarly suggest alteration processes involving rocks other than mantle peridotite alone.

531 Accordingly, alteration of plagioclase formed from melt possibly enriched in incompatible elements such

532 as $\mathrm{Cs}$ and $\mathrm{Rb}$ might provide an explanation more suitable than alteration of residual peridotite at low

533 fluid/rock mass ratio. As discussed earlier, the former scenario is all the more probable given the presence

534 of such enriched protolith elsewhere along the MAR. This, furthermore, alleviates the need to reconcile 
these alkali data in the vent fluids with the Sr isotopic constraints that otherwise predict alteration at a relatively high fluid/rock ratio (Boschi et al., 2008; Foustoukos et al., 2008; Ludwig et al., 2006).

Figure 12b, however, shows that the predicted dissolved silica concentration $(\sim 110 \mathrm{um} / \mathrm{kg})$ is slightly, but significantly, in excess of the maximum value measured for the Beehive vent fluid (Fig. 9). Part of this could be attributed to the modeled temperature being in excess of the "real temperature" in the subseafloor reaction zone at Lost City, although it is unlikely that this could account for more than $\sim 20^{\circ} \mathrm{C}$, based on constraints imposed by anhydrite-fluid equilibria on endmember dissolved $\mathrm{Ca}$ and sulfate concentrations measured for the 2008 vent fluids (Fig. 9). Thus, we need to consider the extent to which dissolved silica may be affected by precipitation/dissolution during ascent to the seafloor where a large thermal gradient is encountered.

\section{3 Reactive Transport Modeling of LCHF fluids}

\subsubsection{Model formulation}

To account for the moderately high silica concentration of BH vent fluids at Lost City, tremolitediopside-serpentine-fluid equilibria at approximately $180-200^{\circ} \mathrm{C}$ is proposed. That the measured temperature is approximately $100^{\circ} \mathrm{C}$ less than this temperature, however, has been interpreted as a result of conductive cooling (Allen and Seyfried, 2004; Foustoukos et al., 2008; Seyfried et al., 2007). Assuming this to be the case, it is important to consider additional modeling results that explicitly take into account rates of mineral precipitation and dissolution as a putative $200^{\circ} \mathrm{C}$ source fluid ascends from depth to the seafloor at Lost City. To accomplish this, we performed 1-dimensional reactive transport simulations with the PFLOTRAN reactive-transport code (Hammond et al., 2012). The depth of the 1dimensional upflow model was set at $750 \mathrm{~m}$ below seafloor, in a manner consistent with constraints imposed by thermal observations from the Atlantis Massif (Blackman et al., 2014). Thus, the base of the system is given a fixed temperature and pressure of $200^{\circ} \mathrm{C}$ and $150 \mathrm{bar}$. No heat or fluid flow is allowed through the sides of the domain, and the thermal gradient along the flow pathway is fixed by the inferred source fluid temperature $\left(200^{\circ} \mathrm{C}\right)$ and maximum measured $\mathrm{BH}$ vent temperature $\left(116^{\circ} \mathrm{C}\right)$. The $200^{\circ} \mathrm{C}$ 
fluid at the base of the modeled domain is less dense than the overlying fluid and therefore rises to the

561 surface through buoyancy-driven flow. The upflowing fluid thereby evolves in both temperature and

562 pressure as it travels upward through the domain, and, to account for this evolution, a thermodynamic

563 database with equilibrium constants calculated along the steam saturation curve was employed for the

564 PFLOTRAN simulations. Because the mineral-fluid and aqueous complexation equilibrium constants in

565 this PFLOTRAN database are slightly different than those used in the calculations discussed above, slight

566 (but insignificant) differences between the calculated $\mathrm{pH}$ and $\mathrm{SiO}_{2}(\mathrm{aq})$ concentrations are apparent within

567 the calculated results.

568 As discussed above, fluids flowing through the Atlantis Massif and feeding the LCHF appear to

569 be controlled by normal faults developed during uplift. Fluid flow within fractured rock tends to be

570 dominated by flow within the fractures, which generally have considerably higher permeability than the

571 unfractured matrix. Accordingly, measurements of permeability in igneous oceanic crust show a strong

572 scale dependency, with larger-scale measurements generally giving higher permeability measurements

573 due to their ability to capture these characteristic features (Becker and Davis, 2003). Discrete modeling of

574 fluid flow within fractures is substantially more computationally intensive than standard continuum

575 modeling and subject to considerable uncertainties due to the inability to characterize fracture spacing and

576 geometry at the appropriate scales. Nonetheless, continuum models have been shown to effectively

577 capture fluid flow, geochemical reactions, and solute fluxes within fractured media, provided that the

578 right parameterizations are employed (Neuman, 1988; Pruess et al., 1990).

Recent 3D, continuum-scale numerical simulations of fluid flow in the Atlantis Massif and LCHF

580 have constrained the permeability of the upflow zone feeding the LCHF to be on the order of $10^{-14}$ to $10^{-15}$

$581 \mathrm{~m}^{2}$ (Titarenko and McCaig, 2014). Three permeabilities spread over this range $\left(1 \times 10^{-15}, 5 \times 10^{-15}\right.$, and 1

$582 \times 10^{-14} \mathrm{~m}^{2}$ ) were employed in the PFLOTRAN simulations. In all simulations, porosity was set to 0.02 ,

583 which is consistent with values measured from drill cores sampled from the Atlantis Massif (Blackman et

584 al., 2006). Two additional "end-member" simulations were run in order to examine the extent of 
permeability and kinetic effects on observed fluid chemistry: 1) full fluid-mineral equilibration as the fluid flows upwards towards the surface, and 2) "conductive cooling," wherein the fluid flows from the deep subsurface to the seafloor in the complete absence of mineral dissolution/precipitation processes. Both of these "end-member" simulations are independent of permeability (i.e. neither involve kinetic constraints), and only depend upon the thermal gradient of the upflow zone.

Kinetic parameters for minerals included in the reactive transport simulations were obtained from the literature (Table 3), and reactive surface area of all phases was set to $0.26 \mathrm{~cm}^{2} / \mathrm{g}$, which is consistent

592 with the $0.7 \mathrm{~m}$ fracture spacing (Kelemen et al., 2011; Paukert et al., 2012). Due to a lack of appropriate 593 parameterizations at the temperature, pressure, and $\mathrm{pH}$ conditions of our simulations, the $\mathrm{pH}$ dependence 594 of mineral-fluid reaction rates (Lasaga, 1998) was not explicitly considered. To remain consistent with the 595 mineral assemblage that we have inferred to buffer fluid chemistry (Fig. 10), the upflow zone was assumed to be comprised of equal parts diopside, chrysotile, and tremolite. The simulated results are insensitive to the modal abundance of these phases, and, regardless of their volume fraction, all minerals listed in Table 3 were allowed to dissolve or precipitate in all model runs. In addition, the saturation states of brucite and talc were monitored, but neither of these phases became supersaturated in any of the reported simulations. Fluids entering the bottom boundary were chemically equilibrated with the

601 diopside-tremolite-chrysotile-anhydrite assemblage at $200^{\circ} \mathrm{C}$, as discussed above (Sect. 4.2).

\subsubsection{Results of reactive transport simulations}

The results of the reactive transport simulations show that interaction of the upflowing fluid with

604 the proposed Si-controlling diopside-tremolite-chrysotile buffer assemblage during ascent to the seafloor 605 is consistent with the observed BH end-member fluid chemistry (Fig. 13). As expected, the lowest 606 permeability simulations behave most similarly to the "full equilibrium" end-member, and the highest 607 permeability simulations behave most similarly to the "conductive cooling" end member, due to the 608 durations of fluid-rock interaction permitted by the assigned value of permeability. Accordingly, if the 609 characteristic permeability of the upflow zone were lower than $1 \times 10^{-15} \mathrm{~m}^{2}$ or higher than $1 \times 10^{-14} \mathrm{~m}^{2}$, the 
610 calculated chemistry would approach the "full equilibrium" and "conductive cooling" scenarios, 611 respectively.

612 The simulated seafloor Si concentrations for all scenarios except pure conductive cooling are

613 within the measured range (Table 1), and the permeability that produces Si concentrations that most

614 closely match end-member BH Si concentrations is $5 \times 10^{-15} \mathrm{~m}^{2}$. Together, these results strongly suggest

615 that the fluids likely undergo at least some degree of fluid-rock interaction during ascent to the sea floor.

616 Notably, the largest changes to Si concentration occur below $200 \mathrm{mbsf}$, and the Si concentrations remain

617 basically constant between that depth and the sea floor (Fig. 13C). The relative lack of Si-changing

618 reactions above $\sim 200$ mbsf suggests that venting fluids are recording Si concentrations obtained at

619 temperatures greater than $\sim 140-150^{\circ} \mathrm{C}$, and that below this temperature the kinetics of the fluid-mineral

620 reactions are sufficiently slow to prevent significant changes in the Si concentrations observed at the 621 seafloor.

The calculated $\mathrm{pH}$ of the vent fluids is subject to unique uncertainties relative to the $\mathrm{Si}$

623 concentration, particularly due to uncertainties attending the calculation of the pressure and temperature 624 dependence of the aqueous complexation reactions. Although all calculated values of $\mathrm{pH}$ are generally

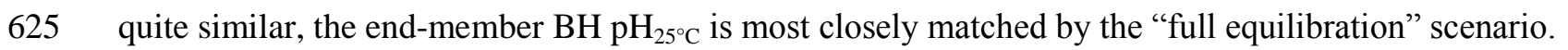
626 This result, alongside that for Si above, implicates permeabilities on the lower end of those put forth by 627 Titarenko and McCaig (2014). These $\mathrm{pH}$ values are generally quite high, which would tend to increase 628 mineral-fluid reaction rate constants relative to near-neutral values.

629 Because some degree of uncertainty attends our inferred equilibration temperature and other 630 researchers (Kelley et al., 2001; Kelley et al., 2005; Lang et al., 2012) have suggested somewhat lower 631 temperatures of equilibration, it is important to discuss the potential implications of a lower-temperature 632 equilibration on potential subseafloor flow properties at LCHF. The Si concentration of a fluid in 633 equilibrium with the diopside-tremolite-chrysotile assemblage decreases from $\sim 110 \mu \mathrm{mol} / \mathrm{kg}$ to $\sim 64$ $634 \mu \mathrm{mol} / \mathrm{kg}$ between $200^{\circ} \mathrm{C}$ and $116^{\circ} \mathrm{C}$ (Fig. 13C). In our model, therefore, lower bottom boundary 
“equilibration temperatures" would require a higher upflow zone permeability in order to preserve the

636 relatively high end-member Si concentrations observed in the BH vent fluids. However, if the depth of

637 the upflow zone is less than $750 \mathrm{~m}$, or if the temperature of equilibration is at a temperature low enough

638 for Si-depleting reactions to become sufficiently ineffective at removing Si from solution, lower up-flow

639 zone permeability is possible.

640 The similarity of all components except Si between the BH and M6 end-member chemistries

641 (Table 2) indicates that the two fluids are derived from a similar source at depth. The lower measured

642 temperature, and the diffusive nature of the M6 fluids, are the only constraints we might use to

643 hypothesize a reason for the lower silica concentrations. A number of reactions could potentially explain

644 how $\sim 50 \mu \mathrm{mol} / \mathrm{kg}$ Si were removed from the M6 fluids without substantially affecting any other chemical

645 components in the fluid. The simplest explanation would be partial or complete re-equilibration with the

646 inferred chrysotile-diopside-tremolite buffer attending increased residence time in the upflow zone (Fig.

647 9). Another possible explanation noted earlier, is the reaction of previously formed brucite, which is

648 known to exist in the chimney structures at LCHF (Ludwig et al., 2006). Both mechanisms nonetheless

649 require the formation of a hydrous silicate phase, which is predicted to be kinetically prohibitive at

650 temperatures below $\sim 150^{\circ} \mathrm{C}$ (Fig. 12). This is in spite of the fact that our calculations predict saturation

651 maxima $(\log \mathrm{Q} / \mathrm{K} \sim 3-9)$ for serpentine/tremolite around $80-100{ }^{\circ} \mathrm{C}$. Thus, barring any microbial

652 involvement, it is possible the kinetic model does not sufficiently account for the unusually high $\mathrm{pH}$ of

653 the Lost City vent fluids. Indeed, because insufficient data exist to include a pH dependency in our

654 calculations of mineral-fluid reaction rates, the rates we calculate may be relatively slow compared to

655 those expected at the relatively high $\mathrm{pH}$ associated with Lost City fluids. Renewed experimental effort

656 into determining the $\mathrm{pH}$ dependency of the kinetics of diopside-chrysotile-tremolite reactions would help

657 to place tighter constraints on reactive transport processes within the Atlantis Massif.

\section{5. SUMMARY AND CONCLUSIONS}


660 City hydrothermal field in 2008. In addition to extending time series observations, these data provide

661 previously unreported information pertinent to the chemical evolution of this unique type of hydrothermal

662 system. For previously measured components, the present dataset suggests little change, confirming the

663 relative stability of heat and mass transport processes for the Lost City system. In general, the two vent

664 sites studied show extensive overlap in the direction and magnitude of chemical changes relative to

665 seawater, suggesting a common source fluid is feeding both sites. We also document previously

666 unrecognized alteration processes affecting fluid chemistry issuing for both sites. Specifically:

667 1. Despite the clear influence of ultramafic lithologies, dissolved silica concentrations are considerably

668 higher than predicted for equilibria involving serpentine-brucite coexistence at all reasonable

669 temperatures. Geochemical modeling indicates these values are consistent with buffering by the

670 following reaction:

$$
\text { Diopside }+0.5 \text { Chrysotile }+\mathrm{SiO}_{2(\text { aq })}=0.5 \mathrm{H}_{2} \mathrm{O}+0.5 \text { Tremolite }
$$

672 We hypothesize that the silica for the Lost City vent fluids need not be provided from an external

673 source, but rather can be derived directly by reaction of a gabbroic plagioclase component intruded

674 into the peridotite host rocks, as observed here and elsewhere. Aluminum and silica released from

675 plagioclase alteration renders brucite unstable, while enhancing formation of tremolite and chlorite. In

676 addition to accounting for the silica in $\mathrm{BH}$ vent fluid, $\mathrm{pH}$ is also buffered at a value consistent with

677 measurement (in-situ and at $25^{\circ} \mathrm{C}$ ), when the activity of dissolved $\mathrm{Ca}$ is explicitly taken into account.

678 2. The dissolved concentration of $\mathrm{Cl}$ indicates a slight depletion relative to seawater. There are a number

679 of processes that can account for this, including $\mathrm{Cl}$ uptake by serpentine and other hydrous alteration

680 phases, as well as dehydration effects caused by the replacement of brucite by serpentine.

681 3. Assuming a depleted mantle protolith, dissolved concentrations of trace alkalis (Cs and $\mathrm{Rb}$, in 682 particular) predict an unusually low fluid/rock mass ratio, in contrast with constraints imposed by 
other chemical and isotopic data. As with silica and $\mathrm{pH}$ buffering reactions, however, these data may also be accounted for by the localized presence and hydrothermal alteration of plagioclase in gabbro.

4. Reactive transport modeling taking explicit account of temperature dependent mineral reaction rates, and permeability values inferred for the Lost City hydrothermal field, suggest dissolved silica concentrations can be expected to decrease on ascent to the seafloor within a narrow range of temperature and permeability, and still account for the BH vent fluid chemistry and temperature. The relatively low dissolved silica concentrations observed for the M6 vent fluid, however, cannot be accounted for by changes in temperature or permeability. Partial re-equilibration attending increased cooling and residence time during upflow is still the best explanation, suggesting kinetic parameters do not sufficiently account for the high $\mathrm{pH}$ of the fluids.

The Lost City hydrothermal system likely represents one of many similar systems associated with hydrothermal alteration at slow spreading ridges, where tectonic processes permit seawater derived fluids to interact with lower crustal lithologies in the shallow footwall of detachment faults. It is only with continued discovery of such systems and application of quantitative tools and new modeling approaches that the origin and evolution of these and related system will become apparent.

\section{ACKNOWLEDGEMENTS}

We thank the Jason team, and Master, officers, and crew of the R/V Revelle, as well as the science party of Cruise KNOX18RR, for the innumerable contributions that enhanced the success of the study. We also acknowledge Dr. Anna-Louise Reysenbach, Chief Scientist, who played such an important role in facilitating all science-related seagoing activities. Jeff Seewald and Peter Saccocia are acknowledged for their valuable contributions to the success of the vent fluid sampling program, and their generosity in sharing dissolved gas data, and thoughtful interpretations of the data, both during and after the cruise. Drew Syverson contributed to the sample processing and analysis of the vent fluid samples reported here, and we are grateful for his efforts. We are grateful to Rick Knurr for the critical role he 
played in the development of new procedures used in the course of the analytical program. Editorial handling by Jeff Alt is appreciated. The paper also benefitted from comments and suggestions by Mike Mottl and Frieder Klein. This research was supported by NSF BIO-OCE 0728391 (A.L.R.), MGG-OCE 0525907 (Jeff Seewald, Chris German, and Tom McCollom), MGG-OCE 0751771, 0813861 (W.E.

Seyfried, Jr., and Kang Ding) and OCE 1426695 (WES).

\section{REFERENCES}

Allen, D.E. and Seyfried, W.E., Jr. (2003) Alteration and mass transfer in the $\mathrm{MgO}-\mathrm{CaO}-\mathrm{FeO}-\mathrm{Fe}_{2} \mathrm{O}_{3}$ $\mathrm{SiO}_{2}-\mathrm{Na}_{2} \mathrm{O}-\mathrm{H}_{2} \mathrm{O}-\mathrm{HCl}$ system at $400^{\circ} \mathrm{C}$ and 500 bars: Implications for $\mathrm{pH}$ and compositional controls on vent fluids from ultramafic-hosted hydrothermal systems at mid-ocean ridges. Geochim. Cosmochim. Acta 67, 1531-1542.

Allen, D.E. and Seyfried, W.E., Jr. (2004) Serpentinization and heat generation: Constraints from Lost City and Rainbow hydrothermal systems. Geochim. Cosmochim. Acta 68, 1347-1355.

Allen, D.E. and Seyfried, W.E., Jr. (2005) REE controls in MOR hydrothermal systems: An experimental study at elevated temperature and pressure. Geochim. Cosmochim. Acta 69, 675-683.

Alt, J.C. and Shanks, W.C., III (2003) Serpentinization of abyssal peridotites from the MARK area, MidAtlantic Ridge: Sulfur geochemistry and reaction modeling. Geochim. Cosmochim. Acta 67, 641653.

Amend, J.P., McCollom, T.M., Hentscher, M. and Bach, W. (2011) Catabolic and anabolic energy for chemolithoautotrophs in deep-sea hydrothermal systems hosted in different rock types. Geochim. Cosmochim. Acta 75, 5736-5748.

Beard, J.S. and Hopkinson, L. (2000) A fossil, serpentinization-related hydrothermal vent, Ocean Drilling Program Leg 173, Site 1068 (Iberia Abyssal Plain): Some aspects of mineral and fluid chemistry. J. Geophys. Res. Solid Earth 105, 16527-16539.

Becker, K. and Davis, E.E. (2003) New evidence for age variation and scale effects of permeabilities of young oceanic crust from borehole thermal and pressure measurements. Earth Planet. Sci. Lett. 210, 499-508.

Berndt, M.E. and Seyfried, W.E., Jr. (1990) Boron, bromine, and other trace elements as clues to the fate of chlorine in mid-ocean ridge vent fluids. Geochim. Cosmochim. Acta 54, 2235-2245.

Berndt, M.E., Seyfried, W.E., Jr. and Beck, J.W. (1988) Hydrothermal alteration processes at mid-ocean ridges: Experimental and theoretical constraints from $\mathrm{Ca}$ and $\mathrm{Sr}$ exchange reactions and $\mathrm{Sr}$ isotopes ratios. J. Geophys. Res. 93, 4573-4583.

Bethke, C.M. and Yeakel, S. (2012) The Geochemist'sWorkbench Release 9.0 Reaction modeling guide. Aqueous Solutions. LLC. 
Blackman, D.K., Ildefonse, B., John, B.E., Ohara, Y., Miller, D.J. and MacLeod, C.J. (2006) Ocean core complex formation, Atlantis Massif. Proceedings of the Integrated Ocean Drilling Program $304 / 305$.

Blackman, D.K., Karson, J.A., Kelley, D.S., Cann, J.R., Früh-Green, G.L., Gee, J.S., Hurst, S.D., John, B.E., Morgan, J., Nooner, S.L., Ross, D.K., Schroeder, T.J. and Williams, E.A. (2002) Geology of the Atlantis Massif (Mid-Atlantic Ridge, $30^{\circ} \mathrm{N}$ ): Implications for the evolution of an ultramafic oceanic core complex. Mar. Geophys. Res. 23, 443-469.

Blackman, D.K., Slagle, A., Guerin, G. and Harding, A. (2014) Geophysical signatures of past and present hydration within a young oceanic core complex. Geophys. Res. Lett. 41, 1179-1186.

Boschi, C., Dini, A., Früh-Green, G.L. and Kelley, D.S. (2008) Isotopic and element exchange during serpentinization and metasomatism at the Atlantis Massif (MAR $\left.30^{\circ} \mathrm{N}\right)$ : Insights from $\mathrm{B}$ and $\mathrm{Sr}$ isotope data. Geochim. Cosmochim. Acta 72, 1801-1823.

Boschi, C., Früh-Green, G.L., Delacour, A., Karson, J.A. and Kelley, D.S. (2006) Mass transfer and fluid flow during detachment faulting and development of an oceanic core complex, Atlantis Massif (MAR 30N). Geochem. Geophys. Geosys. 7, doi:10.1029/2005GC001074.

Bradley, A.M., Tivey, M.K., Liberatore, S.P. and Duester, A.R. (1995) Development and testing of thermocouple/thermistor array packages for monitoring temperature at hydrothermal vent sites. Trans. Am. Geophys. Union (EOS) 71, 411.

Bradley, A.S., Hayes, J.M. and Summons, R.E. (2009) Extraordinary ${ }^{13} \mathrm{C}$ enrichment of diether lipids at the Lost City hydrothermal field indicates a carbon-limited ecosystem. Geochim. Cosmochim. Acta 73, $102-118$.

Brant, C., Coogan, L.A., Gillis, K.M., Seyfried, W.E., Jr., Pester, N.J. and Spence, J. (2012) Lithium and Li-isotopes in young altered upper oceanic crust from the East Pacific Rise. Geochim. Cosmochim. Acta 96, 272-293.

Butterfield, D., Seyfried, W.E., Jr. and Lilley, M. (2003) Composition and evolution of hydrothermal fluids, in: Halbach, P., Tunnicliffe, V., Hein, J.R. (Eds.), Energy and Mass Transfer in Marine Hydrothermal Systems. Dahlem University Press, Berlin, Germany, pp. 123-163.

Cannat, M., Chatin, F., Whitechurch, H. and Ceuleneer, G. (1997a) Gabbroic rocks trapped in the upper mantle at the Mid-Atlantic Ridge, Proceedings of the Ocean Drilling Program: Scientific Results, pp. 243-264.

Cannat, M., Fontaine, F. and Escartin, J. (2010) Serpentinization and Associated Hydrogen and Methane Fluxes at Slow Spreading Ridges, in: Rona, P.A., Devey, C.W., Dyment, J., Murton, B.J. (Eds.), Diversity of Hydrothermal Systems on Slow Spreading Ocean Ridges, pp. 241-264.

Cannat, M., Lagabrielle, Y., Bougault, H., Casey, J., deCoutures, N., Dmitriev, L. and Fouquet, Y. (1997b) Ultramafic and gabbroic exposures at the Mid-Atlantic Ridge: geological mapping in the 15 degrees $\mathrm{N}$ region. Tectonophysics 279, 193-213.

Constantin, M. (1999) Gabbroic intrusions and magmatic metasomatism in harzburgites from the Garrett transform fault: Implications for the nature of the mantle-crust transition at fast-spreading ridges. Contrib. Mineral. Petrol. 136, 111-130.

Delacour, A., Früh-Green, G.L. and Bernasconi, S.M. (2008a) Sulfur mineralogy and geochemistry of serpentinites and gabbros of the Atlantis Massif (IODP Site U1309). Geochim. Cosmochim. Acta 72, 5111-5127. 
Delacour, A., Früh-Green, G.L., Bernasconi, S.M. and Kelley, D.S. (2008b) Sulfur in peridotites and gabbros at Lost City $\left(30^{\circ} \mathrm{N}, \mathrm{MAR}\right)$ : Implications for hydrothermal alteration and microbial activity during serpentinization. Geochim. Cosmochim. Acta 72, 5090-5110.

Fornari, D., Bradley, A., Humphris, S., Walden, B., Duester, A., Catanach, R., Snow, E., Bowen, A., Elder, R., Sellers, W., Hickey, J., Williams, R., Bray, A. and Von Damm, K. (1997) Inductively coupled link (ICL) temperature probes for hot hydrothermal fluid sampling from ROV Jason and DSV Alvin. RIDGE Events 8, 26-30.

Foustoukos, D.I., Savov, I.P. and Janecky, D.R. (2008) Chemical and isotopic constraints on water/rock interactions at the Lost City hydrothermal field, $30^{\circ} \mathrm{N}$ Mid-Atlantic Ridge. Geochim. Cosmochim. Acta 72, 5457-5474.

Frost, B.R. and Beard, J.S. (2007) On silica activity and serpentinization. J. Petrol. 48, 1351-1368.

Früh-Green, G., Connolly, J.A.D. and Plas, A. (2004) Serpentinization of oceanic peridotites: Implications for geochemical cycles and biologic activity, in: Wilcock, W.S.D., DeLong, E.F., Kelley, D.S., Baross, J.A., Cary, S.C. (Eds.), The Subseafloor Biosphere at Mid-Ocean Ridges. American Geophysical Union, pp. 119-135.

Früh-Green, G.L., Kelley, D.S., Bernasconi, S.M., Karson, J.A., Ludwig, K.A., Butterfield, D.A., Boschi, C. and Proskurowski, G. (2003) 30,000 years of hydrothermal activity at the Lost City vent field. Science 301, 495-498.

Hammond, G.E., Lichtner, P.C., Lu, C. and Mills, R.T. (2012) PFLOTRAN: Reactive flow and transport code for use on laptops to leadership-class supercomputers, in: Zhang, F., Yeh, G.T., Parker, J.C. (Eds.), Groundwater Reactive Transport Models, pp. 141-159.

Helgeson, H.C. (1969) Thermodynamics of hydrothermal systems at elevated temperatures and pressures. Am. J. Sci. 267, 729-804.

Helgeson, H.C. and Kirkham, D.H. (1974) Theoretical prediction of the thermodynamic behavior of aqueous electrolytes at high pressures and temperatures. I. Summary of the thermodynamic/elestrostatic properties of the solvent. Am. J. Sci. 274, 1089-1198.

Helgeson, H.C., Kirkham, D.H. and Flowers, G.C. (1981) Theoretical prediction of the thermodynamic behavior of aqueous electrolytes at high pressures and temperatures. IV. Calculation of activity coefficients, osmotic coefficients, and apparent molal and standard and relative partial molal properties to $600^{\circ} \mathrm{C}$ and $5 \mathrm{~kb}$. Am. J. Sci. 281, 1249-1516.

James, R.H., Allen, D.E. and Seyfried, W.E., Jr. (2003) An experimental study of alteration of oceanic crust and terrigenous sediments at moderate temperatures $\left(51\right.$ to $\left.350^{\circ} \mathrm{C}\right)$ : Insights as to chemical processes in near-shore ridge-flank hydrothermal systems. Geochim. Cosmochim. Acta 67, 681691.

Janecky, D.R. and Seyfried, W.E., Jr. (1986) Hydrothermal serpentinization of peridotite within the oceanic crust: Experimental investigations of the mineralogy and major element chemistry. Geochim. Cosmochim. Acta 50, 1357-1378.

Johnson, J.W., Oelkers, E.H. and Helgeson, H.C. (1992) SUPCRT92 - A software package for calculating the standard molal thermodynamic properties of minerals, gases, aqueous species, and reactions from 1-bar to 5000-bar and $0^{\circ} \mathrm{C}$ to $1000^{\circ} \mathrm{C}$. Comp. Geosci. $18,899-947$.

$\mathrm{J} \square$ ns, N., Bach, W. and Klein, F. (2010) Magmatic influence on reaction paths and element transport during serpentinization. Chem. Geol. 274, 196-211. 
Karson, J.A., Früh-Green, G.L., Kelley, D.S., Williams, E.A., Yoerger, D.R. and Jakuba, M. (2006) Detachment shear zone of the Atlantis Massif core complex, Mid-Atlantic Ridge, $30^{\circ} \mathrm{N}$. Geochem. Geophys. Geosys. 7.

Kelemen, P.B., Matter, J., Streit, E.E., Rudge, J.F., Curry, W.B. and Blusztajn, J. (2011) Rates and mechanisms of mineral carbonation in peridotite: Natural processes and recipes for enhanced, in situ CO2 capture and storage, in: Jeanloz, R., Freeman, K.H. (Eds.), Annual Review of Earth and Planetary Sciences, Vol 39, pp. 545-576.

Kelley, D.S., Karson, J.A., Blackman, D.K., Früh-Green, G.L., Butterfield, D.A., Lilley, M.D., Olson, E.J., Schrenk, M.O., Roe, K.K., Lebon, G.T. and Rivizzigno, P. (2001) An off-axis hydrothermal vent field near the Mid-Atlantic Ridge at $30^{\circ}$ N. Nature 412, 145-149.

Kelley, D.S., Karson, J.A., Früh-Green, G.L., Yoerger, D.R., Shank, T.M., Butterfield, D.A., Hayes, J.M., Schrenk, M.O., Olson, E.J., Proskurowski, G., Jakuba, M., Bradley, A., Larson, B., Ludwig, K., Glickson, D., Buckman, K., Bradley, A.S., Brazelton, W.J., Roe, K., Elend, M.J., Delacour, A., Bernasconi, S.M., Lilley, M.D., Baross, J.A., Summons, R.E. and Sylva, S.P. (2005) A serpentinite-hosted ecosystem: The Lost City hydrothermal field. Science 307, 1428-1434.

Klein, F., Bach, W., J $\square$ ns, N., McCollom, T., Moskowitz, B. and Berquo, T. (2009) Iron partitioning and hydrogen generation during serpentinization of abyssal peridotites from $15^{0} \mathrm{~N}$ on the MidAtlantic Ridge. Geochim. Cosmochim. Acta 73, 6868-6893.

Klein, F., Bach, W. and McCollom, T.M. (2013) Compositional controls on hydrogen generation during serpentinization of ultramafic rocks. Lithos 178, 55-69.

Kong, X.-Z., Tutolo, B.M. and Saar, M.O. (2013) DBCreate: A SUPCRT92-based program for producing EQ3/6, TOUGHREACT, and GWB thermodynamic databases at user-defined T and P. Comp. Geosci. 51, 415-417.

Konn, C., Charlou, J.L., Donval, J.P., Holm, N.G., Dehairs, F. and Bouillon, S. (2009) Hydrocarbons and oxidized organic compounds in hydrothermal fluids from Rainbow and Lost City ultramafichosted vents. Chem. Geol. 258, 299-314.

Lang, S., Butterfield, D., Schulte, M., Kelley, D. and Lilley, M. (2010) Elevated concentrations of formate, acetate and dissolved organic carbon found at the Lost City hydrothermal field. Geochim Cosmochim Acta 74, 941 - 952.

Lang, S.Q., Früh-Green, G.L., Bernasconi, S.M. and Butterfield, D.A. (2013) Sources of organic nitrogen at the serpentinite-hosted Lost City hydrothermal field. Geobiology 11, 154-169.

Lang, S.Q., Früh-Green, G.L., Bernasconi, S.M., Lilley, M.D., Proskurowski, G., Mehay, S. and Butterfield, D.A. (2012) Microbial utilization of abiogenic carbon and hydrogen in a serpentinitehosted system. Geochim. Cosmochim. Acta 92, 82-99.

Lasaga, A.C. (1998) Kinetic Theory in the Earth Sciences. Princeton University Press, Princeton, N.J.

Ludwig, K.A., Kelley, D.S., Butterfield, D.A., Nelson, B.K. and Früh-Green, G. (2006) Formation and evolution of carbonate chimneys at the Lost City hydrothermal field. Geochim. Cosmochim. Acta $70,3625-3645$.

Ludwig, K.A., Shen, C.-C., Kelley, D.S., Cheng, H. and Edwards, R.L. (2011) U-Th systematics and Th230 ages of carbonate chimneys at the Lost City hydrothermal field. Geochim. Cosmochim. Acta 75, 1869-1888.

McCaig, A.M., Cliff, R.A., Escartin, J., Fallick, A.E. and MacLeod, C.J. (2007) Oceanic detachment faults focus very large volumes of black smoker fluids. Geol. 35, 935. 
868

869

870

871

872

873

874

875

876

877

878

879

880

881

882

883

884

885

886

887

888

889

890

891

892

893

894

895

896

897

898

899

900

901

902

903

904

905

906

907

908

909

910

McCaig, A.M., Delacour, A., Fallick, A.E., Castelain, T. and Früh-Green, G.L. (2010) Detachment fault control on hydrothermal circulation systems: Interpreting the subsurface beneath the TAG hydrothermal field using the isotopic and geological evolution of oceanic core complexes in the Atlantic, in: Rona, P.A., Devey, C.W., Dyment, J., Murton, B.J. (Eds.), Diversity of Hydrothermal Systems on Slow Spreading Ocean Ridges, pp. 207-239.

McCollom, T.M. and Bach, W. (2009) Thermodynamic constraints on hydrogen generation during serpentinization of ultramafic rocks. Geochim. Cosmochim. Acta 73, 856-875.

Mevel, C. (2003) Serpentinization of abyssal peridotites at mid-ocean ridges. Comp. R. Geosci. 335, 825852.

Miller, J., Kelemen, P.B., Kikawa, E. and Party, O.D.P.L.S.S. (2004) Petrogenesis, alteration, and deformation in mantle peridotite from $14^{\circ}$ to $16^{\circ} \mathrm{N}$ on the Mid-Atlantic Ridge: ODP Leg 209. Geochim. Cosmochim. Acta 68, A689-A689.

Neuman, S.P. (1988) Stochastic continuum representation of fractured rock permeability as an alternative to the REV and fracture network concepts, Groundwater Flow and Quality Modelling Springer Netherlands, pp. 331-362.

Palandri, J.L. and Reed, M.H. (2004) Geochemical models of metasomatism in ultramafic systems: Serpentinization, rodingitization, and sea floor carbonate chimney precipitation. Geochim. Cosmochim. Acta 68, 1115-1133.

Palmer, M.R., London, D., Morgan, G.B. and Babb, H.A. (1992) Experimental determination of fractionation of B-11/B-10 between tourmaline and aqueous vapor - A temperature-dependent and pressure-dependent isotopic system. Chem. Geol. 101, 123-129.

Palmer, M.R., Spivack, A.J. and Edmond, J.M. (1987) Temperature and pH controls over isotopic fractionation during adsorption of boron on marine clay. Geochim. Cosmochim. Acta 51, 23192323.

Paukert, A.N., Matter, J.M., Kelemen, P.B., Shock, E.L. and Havig, J.R. (2012) Reaction path modeling of enhanced in situ $\mathrm{CO} 2$ mineralization for carbon sequestration in the peridotite of the Samail Ophiolite, Sultanate of Oman. Chem. Geol. 330, 86-100.

Pester, N.J., Butterfield, D.A., Foustoukos, D.I., Roe, K., Ding, K., Shank, T.M. and Seyfried, W.E., Jr. (2008) The chemistry of diffuse-flow vent fluids on the Galapagos Rift $\left(86^{\circ} \mathrm{W}\right)$ : Temporal variability and subseafloor phase equilibria controls, in: Lowell, R.P., Seewald, J., Metaxas, A., Perfit, M. (Eds.), Magma to Microbe: Modeling Hydrothermal Processes at Oceanic Spreading Centers.

Pester, N.J., Ding, K. and Seyfried, W.E., Jr. (2014) Magmatic eruptions and iron volatility in deep-sea hydrothermal fluids. Geol.

Pester, N.J., Reeves, E.P., Rough, M.E., Ding, K., Seewald, J.S. and Seyfried, W.E., Jr. (2012) Subseafloor phase equilibria in high-temperature hydrothermal fluids of the Lucky Strike Seamount (Mid-Atlantic Ridge, 37¹7'N). Geochim. Cosmochim. Acta 90, 303-322.

Pester, N.J., Rough, M., Ding, K. and Seyfried, W.E., Jr. (2011) A new Fe/Mn geothermometer for hydrothermal systems: Implications for high-salinity fluids at $13^{\circ} \mathrm{N}$ on the East Pacific Rise. Geochim. Cosmochim. Acta 75, 7881-7892.

Proskurowski, G., Lilley, M., Seewald, J., Fruh-Green, G., Olson, E., Lupton, J., Sylva, S. and Kelley, D. (2008) Abiogenic Hydrocarbon Production at Lost City Hydrothermal Field. Science 319, 604 607. 
Proskurowski, G., Lilley, M.D. and Brown, T.A. (2004) Isotopic evidence of magmatism and seawater bicarbonate removal at the endeavour hydrothermal system. Earth. Planet Sci. Lett. 225, 53-61.

Proskurowski, G., Lilley, M.D., Kelley, D.S. and Olson, E.J. (2006) Low temperature volatile production at the Lost City Hydrothermal Field, evidence from a hydrogen stable isotope geothermometer. Chem. Geol. 229, 331-343.

Pruess, K., Wang, J.S.Y. and Tsang, Y.W. (1990) On thermhydrolic conditions near high-level nuclear wastes emplaced in partially saturated fractured tuff 2 . Effective continuum approximation. Water Resources Research 26, 1249-1261.

Salters, V.J.M. and Stracke, A. (2004) Composition of the depleted mantle. Geochem. Geophys. Geosys. 5.

Sanford, R.F. (1981) Mineralogical and chemical effects of hydration reactions and applications to serpentinization. Am. Mineral. 66, 290-297.

Schroeder, T., John, B. and Frost, B.R. (2002) Geologic implications of seawater circulation through peridotite exposed at slow-spreading mid-ocean ridges. Geol. 30, 367-370.

Seewald, J.S., Doherty, K.W., Hammar, T.R. and Liberatore, S.P. (2002) A new gas-tight isobaric sampler for hydrothermal fluids. Deep Sea Research Part I: Oceanographic Research Papers 49, 189-196.

Seewald, J.S. and Seyfried, W.E., Jr. (1990) The effect of temperature on metal mobility in subseafloor hydrothermal systems: Constraints from basalt alteration experiments. Earth Planet. Sci. Lett. $101,388-403$.

Seewald, J.S., Zolotov, M.Y. and McCollom, T. (2006) Experimental investigation of single carbon compounds under hydrothermal conditions. Geochim. Cosmochim. Acta 70, 446-460.

Seyfried, W.E., Jr. and Dibble, W.E., Jr. (1980) Seawater-peridotite interaction at $300^{\circ} \mathrm{C}$ and 500 bars: Implications for the origin of oceanic serpentinites. Geochim. Cosmochim. Acta 44, 309-322.

Seyfried, W.E., Jr., Foustoukos, D.I. and Fu, Q. (2007) Redox evolution and mass transfer during serpentinization: An experimental and theoretical study at $200^{\circ} \mathrm{C}, 500$ bar with implications for ultramafic-hosted hydrothermal systems at Mid-Ocean Ridges. Geochim. Cosmochim. Acta 71, 3872-3886.

Seyfried, W.E., Jr., Janecky, D.R. and Mottl, M.J. (1984) Alteration of the oceanic crust: implications for geochemical cycles of lithium and boron, Geochim. Cosmochim. Acta, pp. 557-569.

Seyfried, W.E., Jr., Pester, N. and Fu, Q. (2010) Phase equilibria controls on the chemistry of vent fluids from hydrothermal systems on slow spreading ridges: Reactivity of plagioclase and olivine solid solutions and the pH-silica connection, in: Rona, P., Davey, C., Dyment, J., Murton, B. (Eds.), Diversity of Hydrothermal Systems on Slow Spreading Ocean Ridges. American Geophysical Monograph.

Seyfried, W.E., Jr., Pester, N.J., Ding, K. and Rough, M. (2011) Vent fluid chemistry of the Rainbow hydrothermal system $\left(36^{\circ} \mathrm{N}\right.$, MAR): Phase equilibria and in situ $\mathrm{pH}$ controls on subseafloor alteration processes. Geochim. Cosmochim. Acta 75, 1574-1593.

Seyfried, W.E., Jr., Seewald, J.S., Berndt, M.E., Ding, K. and Foustoukos, D.I. (2003) Chemistry of hydrothermal vent fluids from the Main Endeavour Field, Northern Juan de Fuca Ridge: Geochemical controls in the aftermath of June 1999 seismic events. J. Geophys. Res. 108, 2429, doi: 2410.1029/2002JB001957. 
Sharp, Z.D. and Barnes, J.D. (2004) Water-soluble chlorides in massive sea-floor serpentinites: A source of chloride in subduction zones. Earth Planet. Sci. Lett. 226, 243-254.

Sleep, N.H., Meibom, A., Fridriksson, T., Coleman, R.G. and Bird, D.K. (2004) $\mathrm{H}_{2}$-rich fluids from serpentinization: Geochemical and biotic implications. Proceedings of the National Academy of Sciences of the United States of America 101, 12818-12823.

Spivack, A.J. and Edmond, J.M. (1987) Boron isotope exchange between seawater and the oceanic crust. Geochim. Cosmochim. Acta 51, 1033-1045.

Sverjensky, D.A., Shock, E.L. and Helgeson, H.C. (1997) Prediction of the thermodynamic properties of aqueous metal complexes to $1000^{\circ} \mathrm{C}$ and $5 \mathrm{~kb}$. Geochim. Cosmochim. Acta 61, 1359-1412.

Tamura, A., Arai, S., Ishimaru, S. and Andal, E. (2008) Petrology and geochemistry of peridotites from IODP Site U1309 at Atlantis Massif, MAR 30 N: Micro- and macro-scale melt penetrations into peridotites. Contrib. Mineral. Petrol. 155, 491-509.

Titarenko, S. and McCaig, A. (2014) Constraints on the Lost City hydrothermal system from borehole thermal data: 3D models of heat flow and hydrothermal circulation in an oceanic core complex. Eos Trans. AGU V21A-4729.

Tutolo, B.M., Kong, X.-Z., Seyfried, W.E., Jr. and Saar, M.O. (2014) Internal consistency in aqueous geochemical data revisited: applications to the aluminum system. Geochim Cosmochim Acta 133, 216-234.

Tutolo, B.M., Schaen, A.T., Saar, M.O. and Seyfried Jr, W.E. (2015) Implications of the redissociation phenomenon for mineral-buffered fluids and aqueous species transport at elevated temperatures and pressures. Appl. Geochem. 55, 119-127.

Von Damm, K.L. (1995) Controls on the chemistry and temporal variability of seafloor hydrothermal fluids, in: Humphris, S.E., Zierenberg, R.A., Mullineaux, L.S., Thompson, R.E. (Eds.), Seafloor Hydrothermal Systems: Physical, Chemical, Biologic and Geologic Interactions. American Geophysical Union, pp. 222-248.

Von Damm, K.L. (2000) Chemistry of hydrothermal vent fluids from $9^{\circ}-10^{\circ}$ N, East Pacific Rise: "Time zero," the immediate posteruptive period. J. Geophys. Res. 105, 11203-11222.

Von Damm, K.L., Bray, A.M., Buttermore, L.G. and Oosting, S.E. (1998) The geochemical controls on vent fluids from the Lucky Strike vent field, Mid-Atlantic Ridge. Earth Planet. Sci. Lett. 160, 521-536.

Von Damm, K.L., Edmond, J.L., Grant, B., Measures, C.I., Walden, B. and Weiss, R.F. (1985) Chemistry of submarine hydrothermal solutions at $21^{\circ} \mathrm{N}$, East Pacific Rise. Geochim. Cosmochim. Acta 49, 2221-2237.

Wetzel, L.R. and Shock, E.L. (2000) Distinguishing ultramafic- from basalt-hosted submarine hydrothermal systems by comparing calculated vent fluid compositions. J. Geophys. Res. 105, 8319-8340.

Wu, S.J., Yang, C.J., Pester, N.J. and Chen, Y. (2011) A new hydraulically actuated titanium sampling valve for deep-sea hydrothermal fluid samplers. IEEE Journal of Oceanic Engineering 36, 462469. 


\section{FIGURE CAPTIONS}

994

995

996

Fig. 1. Lost City Hydrothermal Field (LCHF) adapted from Kelley et al. (2005) showing location on the southern wall of the Atlantis Massif (A) (Blackman et al., 2006; Blackman et al., 2014; Kelley et al., 2001; Kelley et al., 2005). The symbol "B" on this illustration marks the approximate location on the south wall of the Lost City vent system. Bathymetric map of the Lost City Hydrothermal Field showing vent locations (B). The symbols highlight vents 3, 6, C and Beehive (BH), located near the center of the field (“B”). Owing to overall cruise objectives, BH and M6 vent fluids were repeatedly sampled, providing a more complete measure of the effect of the full range of sampling related variability that can contribute to the reported concentrations of hydrothermal vent fluid chemistry at these two sites. The figure was kindly provided by Dr. Deborah Kelley.

Fig. 2. Hydrothermal vent fluid being sampled with isobaric gas tight samplers (Seewald et al., 2002) at Beehive structure, southern Atlantis Massif. This location (see Fig. 1) is one of the few areas of focused flow from which hydrothermal fluid could be effectively acquired owing to convenient access to the vent orifice. In many other areas, hydrothermal fluid vented more diffusively from carbonate-hosted structures, enhancing the likelihood of seawater entrainment. Vent fluid temperatures measured at this location were in the vicinity of $\sim 90^{\circ} \mathrm{C}$, although temperature data for one sample recovered from this site indicated a temperature of $116^{\circ} \mathrm{C}$.

Fig. 3. Dissolved sulfate (A) and chloride (B) in LC vent fluids plotted against dissolved Mg, which is an indicator of seawater entrainment. Thus, hydrothermal endmember for these and other components is calculated from the Y intercept of the regression line. Bottom seawater sampled at LC is indicted by the triangle (blue). One of the 2 samples at the "M vent site" (red circle) actually acquired seawater owing to an unfortunate offset separation of snorkel and the routinely attached thermocouple. Thus, we were measuring a fluid temperature different than that which was sampled. All of the hydrothermal vent fluids sampled at the beehive vent (black square) and the one other sample from M6 reveal very low concentrations of $\mathrm{Mg}$ and general agreement in the regressed endmember concentrations of dissolved 
sulfate and chloride. Although low dissolved sulfate concentrations are typical of hydrothermal vent

1021 fluids at mid-ocean ridges, for the vents sampled, the endmember concentration is well above zero, in

1022 keeping with anhydrite buffering (see below). The depletion in dissolved $\mathrm{Cl}$ relative to seawater (B) is a

1023 more surprising discovery, and rarely encountered, especially in the absence of phase separation effects,

1024 which can be ruled out in this case (see text).

1025

1026 Fig. 4. Endmember concentrations of dissolved $\mathrm{Na}(\mathrm{A})$ and $\mathrm{Ca}(\mathrm{B})$ in Lost City hydrothermal vent fluids 1027 and local bottom seawater. See text and Fig. 3 for additional details.

1029 Fig. 5. Endmember concentrations of $\mathrm{Cs}(\mathrm{A}), \mathrm{Rb}(\mathrm{B}), \mathrm{Li}(\mathrm{C})$ and $\mathrm{Sr}(\mathrm{D})$ in LC hydrothermal vent fluids 1030 and local bottom seawater. See text and Fig. 3 for additional details.

1032 Fig. 6. Endmember concentration of dissolved boron in LC hydrothermal vent fluid and local seawater. 1033 See text and Fig. 3 for additional details.

Fig. 7. Endmember concentrations of dissolved silica in LC vent fluids and local seawater. Unlike other components, distinct differences exist between fluids at the two vent sites, apparently due to differential

1037 effects of cooling and reaction. The diffusively venting M6 site fluid conductively cools to temperatures 1038 near $50^{\circ} \mathrm{C}$, apparently allowing the fluids to lose silica by reaction. This seems not to be the case for the 1039 beehive $(\mathrm{BH})$ vent fluids, which are enriched in silica by a factor of approximately 3 relative to seawater 1040 and the M6 site vent fluids. See text and Fig. 3 for additional details. It is important to note that even the 1041 silica in seawater is well in excess of that predicted for brucite-serpentine equilibrium, suggesting sources 1042 of silica from lithologies other than peridotite. This is an important finding with implications for heat and 1043 mass transfer reactions at LCHF and other ultramafic-hosted hydrothermal systems. 
1045 Fig. 8. Endmember concentrations of $\mathrm{H}_{2}(\mathrm{~A})$ and $\mathrm{CH}_{4}(\mathrm{~B})$ in $\mathrm{LC}$ hydrothermal vent fluids and local 1046 bottom seawater (See text and Fig. 3 for additional details.

1048 Fig. 9. Predicted concentrations of dissolved silica as a function of temperature for two reactions often 1049 implicated as a means of controlling Si in ultramafic-hosted hydrothermal vent fluid systems. The first 1050 reaction, which is capable of buffering silica at relatively high values, involves the coexistence of 1051 chrysotile-tremolite-diopside-fluid, while the second is more typical of peridotite-seawater interaction 1052 where olivine and orthopyroxene hydrolysis give rise to chrysotile-brucite-diopside. This reaction has 1053 long been recognized for low silica concentrations, as shown. For comparison, the maximum dissolved 1054 silica measured for BH vent fluid is shown suggesting control by the high-Si buffer reaction. Assuming 1055 this to be the case, the dissolved silica of the $\mathrm{BH}$ vent fluid suggests a subseafloor temperature of approximately $180^{\circ} \mathrm{C}$, which is in good agreement with constraints imposed by anhydrite-fluid equilibria,

1057 as illustrated. Somewhat higher and lower temperatures are permissible when uncertainties in analytical 1058 and thermodynamic data are taken into account. Dissolved Si for M6 vent fluid is lower than $180^{\circ} \mathrm{C}$, 1059 consistent with greater reaction on ascent to the seafloor at lower temperatures. Calculations were 1060 performed using GWB software ((Bethke and Yeakel, 2012) and thermodynamic data for minerals and 1061 aqueous fluids obtained from the SUPCRT92 database with revisions suggested by Tutlolo et al. (2014).

1063 Fig. 10. Activity diagram in the $\mathrm{CaO}-\mathrm{MgO}-\mathrm{SiO}_{2}-\mathrm{NaCl}-\mathrm{H}_{2} \mathrm{O}-\mathrm{HCl}$ system at $200^{\circ} \mathrm{C}$ and 150 bars (Bethke 1064 and Yeakle, 2012) using thermodynamic data described in section 4.2. Importantly, the relatively high $1065 \log \mathrm{aCa}^{++} / \mathrm{a}^{2} \mathrm{H}^{+}$ratio imposed by the coexistence of chrysotile-diopside-brucite and chrysotile-diopside1066 tremolite, respectively plays a key role in controlling dissolved silica in ultramafic-hosted hydrothermal 1067 systems. The latter mineral-fluid system likely accounts for the relatively high concentration of dissolved 1068 silica at Lost City. 
1070 Fig. 11. The effect of conductive cooling on $\mathrm{pH}$ from an inferred maximum temperature of $200^{\circ} \mathrm{C}$ to near 1071 ambient conditions when $\mathrm{pH}$ is buffered by chrysotile-diopside-brucite (black squares), and chrysotile1072 diopside-tremolite (red circle) - fluid systems, respectively. The measured pH at Lost City (star, and 1073 triangle) agree well with the latter chemical/mineralogical system, as does dissolved silica (Fig. 9, 10).

1075 Fig. 12. Reaction path model that simulates the incremental addition of seawater $(5 \mathrm{~kg})$ to peridotite (1 $1076 \mathrm{~kg}$ ) at $200^{\circ} \mathrm{C}$ and 150 bar. The peridotite has a composition consistent with that used by McCollom and 1077 Bach (2009) in their study modeling the effect of seawater-peridotite interaction on alteration mineral 1078 formation and $\mathrm{H}_{2}$ generation at a range of temperatures. In contrast with this earlier study, however, 1079 mineral solid solutions of stable alteration mineral phases were not included here. Thus, our reference to 1080 solid solutions of unstable mineral reactants (e.g., olivine, orthopyroxene) simply serve the purpose of 1081 defining mineralogical and chemical mass balances. In addition to seawater, however, the present model 1082 allows the simultaneous addition of up to 200 grams of plagioclase (An80). Data show that the reaction of 1083 plagioclase with completely serpentinized peridotite effectively removes brucite as an alteration product 1084 owing to replacement by chlorite and tremolite (A). Anhydrite, chrysotile, chlorite, tremolite and diopside 1085 are present at the end of the simulation. Thus, the reaction of even small amounts of plagioclase can 1086 provide sufficient aluminum to change the chemical system and preclude the existence of brucite as a 1087 constraint lowering dissolved silica (B). This is an important observation with implications for the 1088 interpretation of the chemical evolution of the relatively high silica, high pH Lost City vent fluids. 1089 Calculations were performed using GWB software (Bethke and Yeakel, 2012) and thermodynamic data

1090 for minerals and aqueous fluids obtained from the SUPCRT92 database with revisions suggested by 1091 Tutolo et al (2014).

1093 Fig. 13. Results of 1-dimensional reactive transport simulations of the geochemical evolution of Beehive 1094 vent fluids as they ascend from the maximum observed depth of hydrothermal circulation in the Atlantis 
1095 Massif (750 m, Blackman et al., 2014) to the sea floor. The thermal profile was fixed as shown in panel

1096 A in order to simulate fluid flow between the inferred diopside-tremolite-chrysotile equilibration

1097 temperature $\left(200^{\circ} \mathrm{C}\right)$ and the maximum observed vent temperature in the Beehive structure $\left(116^{\circ} \mathrm{C}\right)$. The

1098 evolution of $\mathrm{pH}(\mathrm{B})$ and total dissolved silica (C) during fluid ascent to the seafloor was simulated for 5

1099 different scenarios, including full mineral-fluid equilibration; permeabilities of $1 \times 10^{-15}, 5 \times 10^{-15}, 1 \times 10^{-14} \mathrm{~m}^{2}$

1100 (representative of the likely range of LCHF upflow zone permeabilities reported by Titarenko and

1101 McCaig (2014)); and "conductive cooling" (i.e., fluid flow from the deep subsurface to the seafloor with

1102 no mineral dissolution/precipitation). It is important to note that the full equilibrium and "conductive

1103 cooling" results are independent of permeability and only dependent on the thermal gradient of the

1104 upflow zone. The calculated values of $\mathrm{pH}_{25^{\circ} \mathrm{C}}$ for each scenario are indicated above panel $\mathrm{B}$, and the end-

1105 member silica concentration for the Beehive vent fluids $(72.7 \mu \mathrm{mol} / \mathrm{kg}$ - see Table 2$)$ is indicated above

1106 panel C. End-member (measured) $\mathrm{pH}_{25^{\circ} \mathrm{C}}$ for the Beehive vent fluids is 10.5 (Table 2).

1107 
Table 1. Dissolved chemistry ${ }^{*}$ of selected vent fluids from the Lost City Hydrothermal Field.

\begin{tabular}{|c|c|c|c|c|c|c|c|c|c|c|c|c|c|c|c|c|c|c|c|c|}
\hline Vent & Sample & $\mathrm{T}^{\circ} \mathrm{C}$ & $\begin{array}{c}\mathrm{pH} \\
\left(25^{\circ}\right)\end{array}$ & $\begin{array}{c}\mathrm{Cl} \\
\mathrm{mm}\end{array}$ & $\begin{array}{c}\mathrm{Br} \\
\mu \mathrm{m}\end{array}$ & $\begin{array}{l}\mathrm{SO} 4 \\
\mathrm{~mm}\end{array}$ & $\begin{array}{l}\mathrm{Mg} \\
\mathrm{mm}\end{array}$ & $\begin{array}{l}\mathrm{Na} \\
\mathrm{mm}\end{array}$ & $\begin{array}{l}\mathrm{K} \\
\mathrm{mm}\end{array}$ & $\begin{array}{l}\mathrm{Ca} \\
\mathrm{mm}\end{array}$ & $\begin{array}{l}\mathrm{Sr} \\
\mu \mathrm{m}\end{array}$ & $\begin{array}{l}\mathrm{Li} \\
\mu \mathrm{m}\end{array}$ & $\begin{array}{l}\text { B } \\
\mu \mathrm{m}\end{array}$ & $\begin{array}{l}\mathrm{Rb} \\
\mu \mathrm{m}\end{array}$ & $\begin{array}{l}\text { Cs } \\
\mathrm{nm}\end{array}$ & $\begin{array}{l}\text { Si } \\
\mu \mathrm{m}\end{array}$ & $\begin{array}{l}\text { Fe } \\
\mu \mathrm{m}\end{array}$ & $\begin{array}{l}\mathrm{CH}_{4} \\
\mathrm{~mm}\end{array}$ & $\begin{array}{l}\mathrm{H}_{2} \\
\mathrm{~mm}\end{array}$ & $\begin{array}{l}\mathrm{H}_{2} \mathrm{~S} \\
\mathrm{~mm}\end{array}$ \\
\hline $\mathrm{M6}^{* *}$ & $\begin{array}{l}\text { J2-361 } \\
\text { IGT8 }\end{array}$ & 53 & 7.57 & 554 & 831 & 27.2 & 52.8 & 483 & 10.5 & 10.9 & 91 & 25 & 415 & 1.5 & 5 & 25.8 & - & - & - & - \\
\hline M6 & $\begin{array}{l}\text { J2-362 } \\
\text { IGT2 }\end{array}$ & 75 & 10.5 & 541 & 813 & 3.64 & 1.6 & 494 & 10.5 & 26.4 & 103 & 43 & 52 & 2.8 & 13 & 30.5 & - & 1.22 & 10.4 & 0.14 \\
\hline M6 & $\begin{array}{l}\text { J2-362 } \\
\text { IGT4 }\end{array}$ & 78 & 10.5 & 541 & 803 & 3.51 & 1.3 & 494 & 10.5 & 26.6 & 102 & 43 & 51 & 2.8 & 17 & 24.2 & - & 1.18 & 9.9 & 0.22 \\
\hline $\mathrm{BH}$ & $\begin{array}{l}\text { J2-360 } \\
\text { IGT2 }\end{array}$ & 116 & 10.4 & 542 & 844 & 4.12 & 1.9 & 491 & 10.5 & 26.5 & 101 & 44 & 50 & 2.8 & 20 & 68.7 & 1.2 & 1.32 & 11.5 & - \\
\hline $\mathrm{BH}$ & $\begin{array}{l}\text { J2-360 } \\
\text { IGT6 }\end{array}$ & 90 & 10.6 & 541 & 912 & 3.46 & 0.1 & 485 & 10.3 & 26.9 & 99 & 44 & 39 & 2.8 & 14 & 73.3 & 1.1 & - & - & - \\
\hline $\mathrm{BH}$ & $\begin{array}{l}\text { J2-360 } \\
\text { CGTR } \\
\end{array}$ & 96 & 10.1 & 542 & 849 & 5.01 & 3.6 & 485 & 10.3 & 27.1 & 107 & 43 & 68 & 2.8 & 17 & 60.0 & - & 1.36 & 12 & - \\
\hline $\mathrm{BH}$ & $\begin{array}{l}\text { J2-361 } \\
\text { IGT5 }\end{array}$ & 90 & 10.5 & 541 & 850 & 3.99 & 1.4 & 495 & 10.5 & 26.9 & 102 & 43 & 51 & 2.8 & 13 & 60.5 & 0.6 & 1.23 & 10.5 & 0.07 \\
\hline $\mathrm{BH}$ & $\begin{array}{l}\text { J2-361 } \\
\text { IGT6 }\end{array}$ & 90 & 10.6 & 543 & 861 & 3.61 & 1.1 & 492 & 10.5 & 27.5 & 98 & 43 & 45 & 2.7 & 14 & - & 3.4 & - & - & - \\
\hline $\mathrm{BH}$ & $\begin{array}{l}\mathrm{J} 2-361 \\
\mathrm{CGTB}\end{array}$ & 85 & 10.2 & 543 & 818 & 6.16 & 6.6 & 490 & 10.4 & 25.2 & 101 & 41 & 80 & 2.7 & 14 & 67.4 & 1.9 & 1.11 & 9.4 & 0.21 \\
\hline $\mathrm{BH}$ & $\begin{array}{l}\text { J2-361 } \\
\text { CGT-Wu }\end{array}$ & 94 & 10.5 & 543 & 820 & 4.24 & 2.4 & 493 & 10.5 & 26.5 & 101 & 42 & 52 & 2.7 & 14 & 92.1 & 1.7 & 1.25 & 10.5 & - \\
\hline & Seawater & 2 & 8.0 & 554 & 857 & 28.7 & 53.3 & 475 & 10.3 & 10.4 & 92 & 24 & 412 & 1.4 & 2.3 & 25 & 0 & 0 & 0 & 0 \\
\hline
\end{tabular}

*mm=mmol/kg; $\mu \mathrm{m}=\mu \mathrm{mol} / \mathrm{kg} ; \mathrm{nm}=\mathrm{nmol} / \mathrm{kg}$, Seawater = LC bottom water, (-) = not analyzed

** Failed sample (see text) 
Table 2. Endmember concentrations* of vent fluid chemistry from the Lost City Hydrothermal Field.

\begin{tabular}{|c|c|c|c|c|c|c|c|c|c|c|c|c|c|c|c|c|}
\hline Vent & $\begin{array}{c}\mathrm{pH} \\
\left(25^{\circ}\right)\end{array}$ & $\begin{array}{c}\mathrm{Cl} \\
\mathrm{mm}\end{array}$ & $\begin{array}{c}\mathrm{Br} \\
\mathrm{um}\end{array}$ & $\begin{array}{c}\mathrm{SO}_{4} \\
\mathrm{~mm}\end{array}$ & $\begin{array}{c}\mathrm{Na} \\
\mathrm{mm}\end{array}$ & $\begin{array}{c}\mathrm{Mg} \\
\mathrm{mm}\end{array}$ & $\begin{array}{c}\mathrm{K} \\
\mathrm{mm}\end{array}$ & $\begin{array}{c}\mathrm{Ca} \\
\mathrm{mm}\end{array}$ & $\begin{array}{c}\mathrm{Sr} \\
\mathrm{um}\end{array}$ & $\begin{array}{c}\mathrm{Li} \\
\mathrm{um}\end{array}$ & $\begin{array}{c}\mathrm{B} \\
\mathrm{um}\end{array}$ & $\begin{array}{c}\mathrm{Rb} \\
\mathrm{um}\end{array}$ & $\begin{array}{c}\mathrm{Cs} \\
\mathrm{nm}\end{array}$ & $\begin{array}{c}\mathrm{Si} \\
\mathrm{um}\end{array}$ & $\begin{array}{c}\mathrm{CH}_{4} \\
\mathrm{~mm}\end{array}$ & $\begin{array}{c}\mathrm{H}_{2} \\
\mathrm{~mm}\end{array}$ \\
\hline $\mathrm{M6}^{* *}$ & 10.5 & 541 & 815 & 3.5 & 494 & 1.3 & 10.5 & 26.6 & 102 & 43 & 51 & 2.8 & 17 & 24.2 & 1.20 & 9.9 \\
\hline $\mathrm{BH}$ & 10.6 & 541 & 851 & 3.2 & 494 & 0.0 & 10.5 & 27.4 & 102 & 46 & 38 & 2.8 & 16 & 72.7 & 1.26 & 10.8 \\
\hline Seawater & 8.0 & 554 & 857 & 28.2 & 475 & 53.3 & 10.3 & 10.4 & 92 & 24 & 412 & 1.4 & 2.3 & 25 & 0 & 0 \\
\hline
\end{tabular}

* $\mathrm{mm}=\mathrm{mmol} / \mathrm{kg} ; \mu \mathrm{m}=\mu \mathrm{mol} / \mathrm{kg} ; \mathrm{nm}=\mathrm{nmol} / \mathrm{kg}$, Seawater $=\mathrm{LC}$ bottom water

** Endmember defined as fluid with lowest measured Mg concentration (see Table 1). 
Table 3. Kinetic parameters used in reactive transport simulations

\begin{tabular}{|c|c|c|c|c|}
\hline Mineral & $\begin{array}{l}\text { Surface Area } \\
\left(\mathrm{cm}^{2} / \mathrm{g}\right)\end{array}$ & $\begin{array}{c}\log (\text { Rate } \\
\text { Constant) } \\
\left(\mathrm{mol} / \mathrm{cm}^{2} / \mathrm{s}\right)\end{array}$ & $\begin{array}{c}\text { Activation } \\
\text { Energy } \\
\text { (kJ/mol) }\end{array}$ & Reference \\
\hline Chrysotile & 0.26 & -13.58 & 73.5 & Palandri and Kharaka (2004) \\
\hline Tremolite & 0.26 & -14.6 & 94.4 & $\begin{array}{l}\text { Murphy and Helgeson (1987); } \\
\text { Pokrovsky and Schott (2000) }\end{array}$ \\
\hline Diopside & 0.26 & -14.79 & 40.6 & Knauss et al. (1993) \\
\hline Anhydrite & 0.26 & -7.19 & 14.3 & Palandri and Kharaka (2004) \\
\hline
\end{tabular}


Figure 1
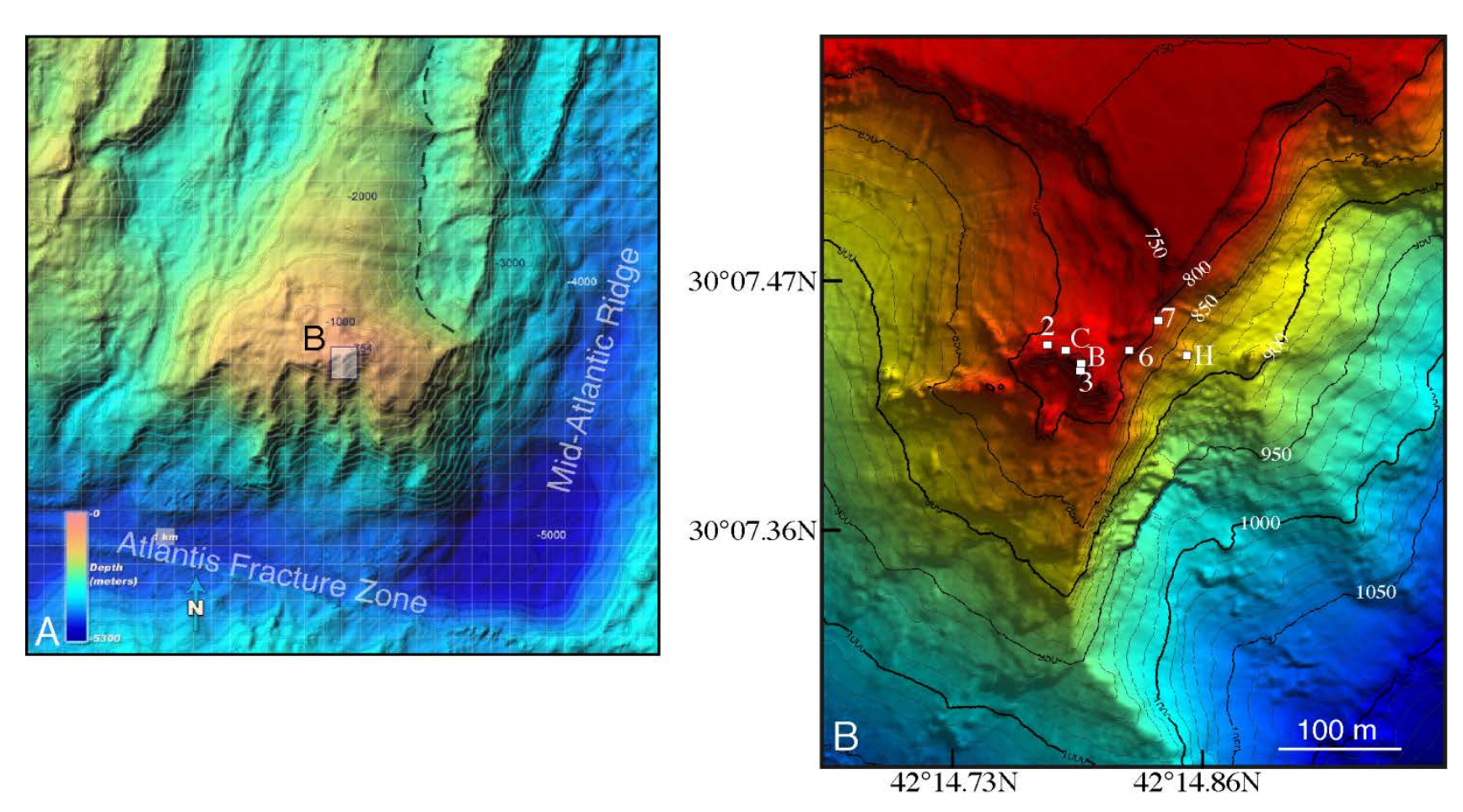

Fig. 1. 


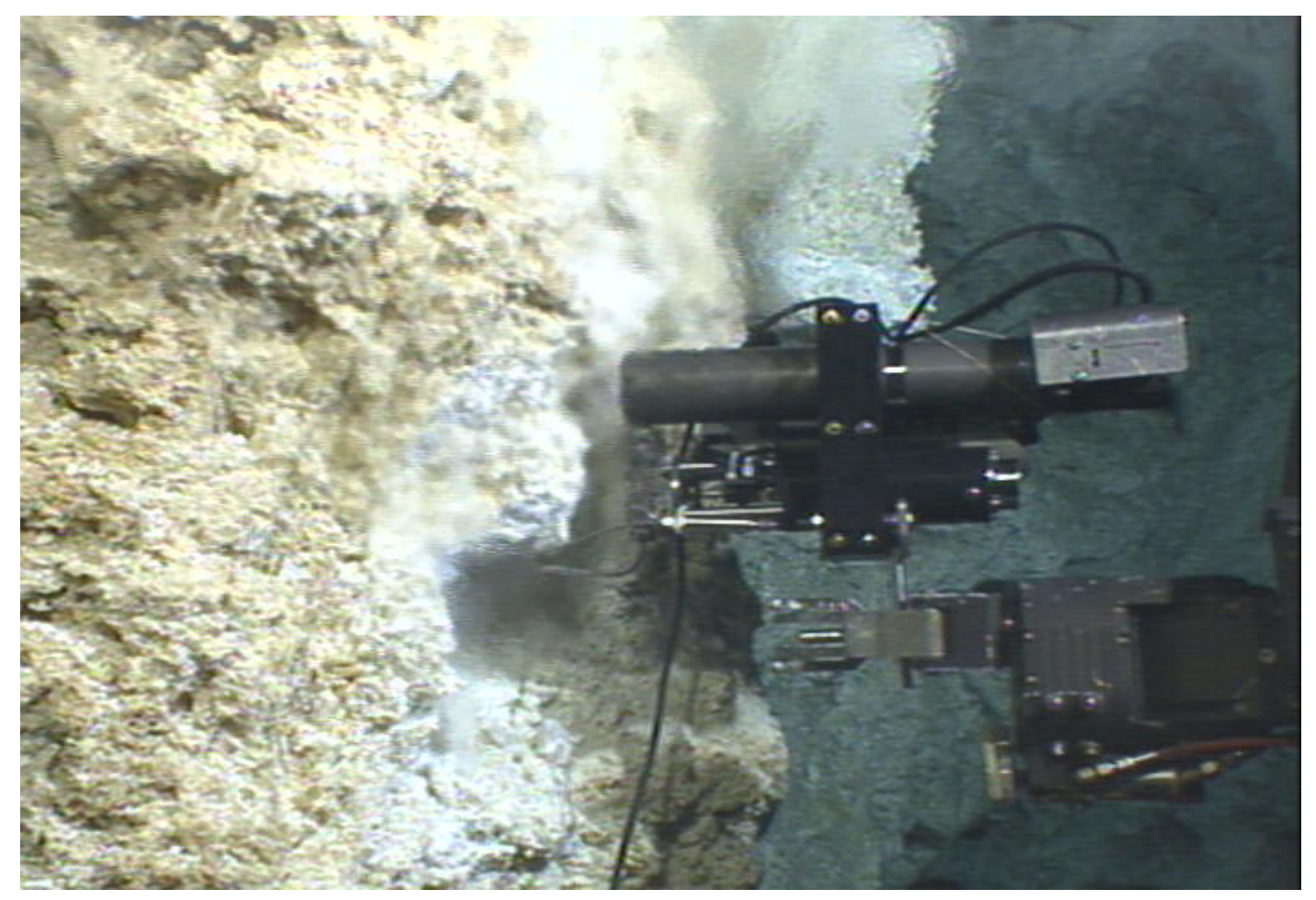

Fig. 2.

Figure 2 

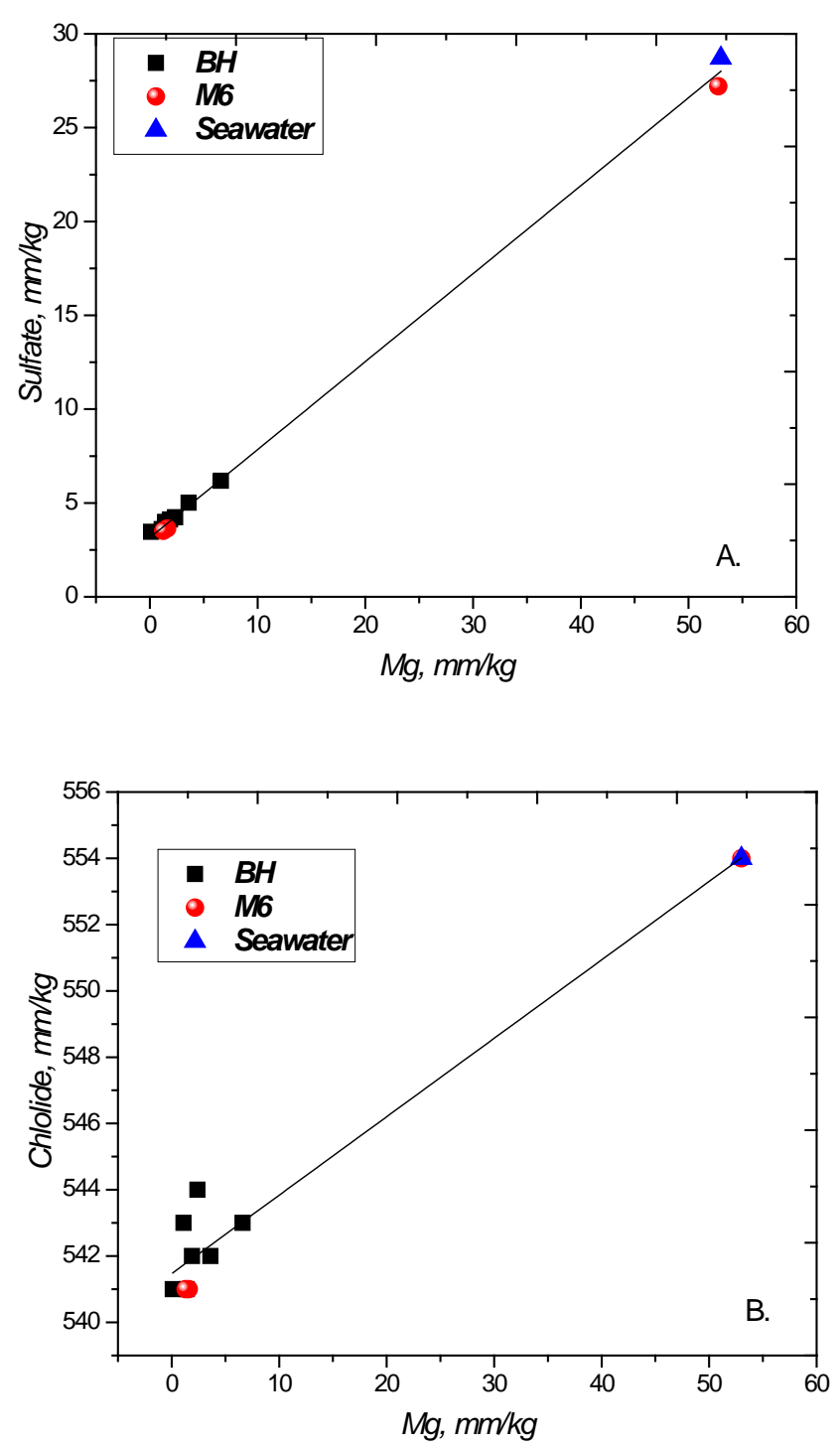

Fig. 3

Figure 3 
Fig. 5
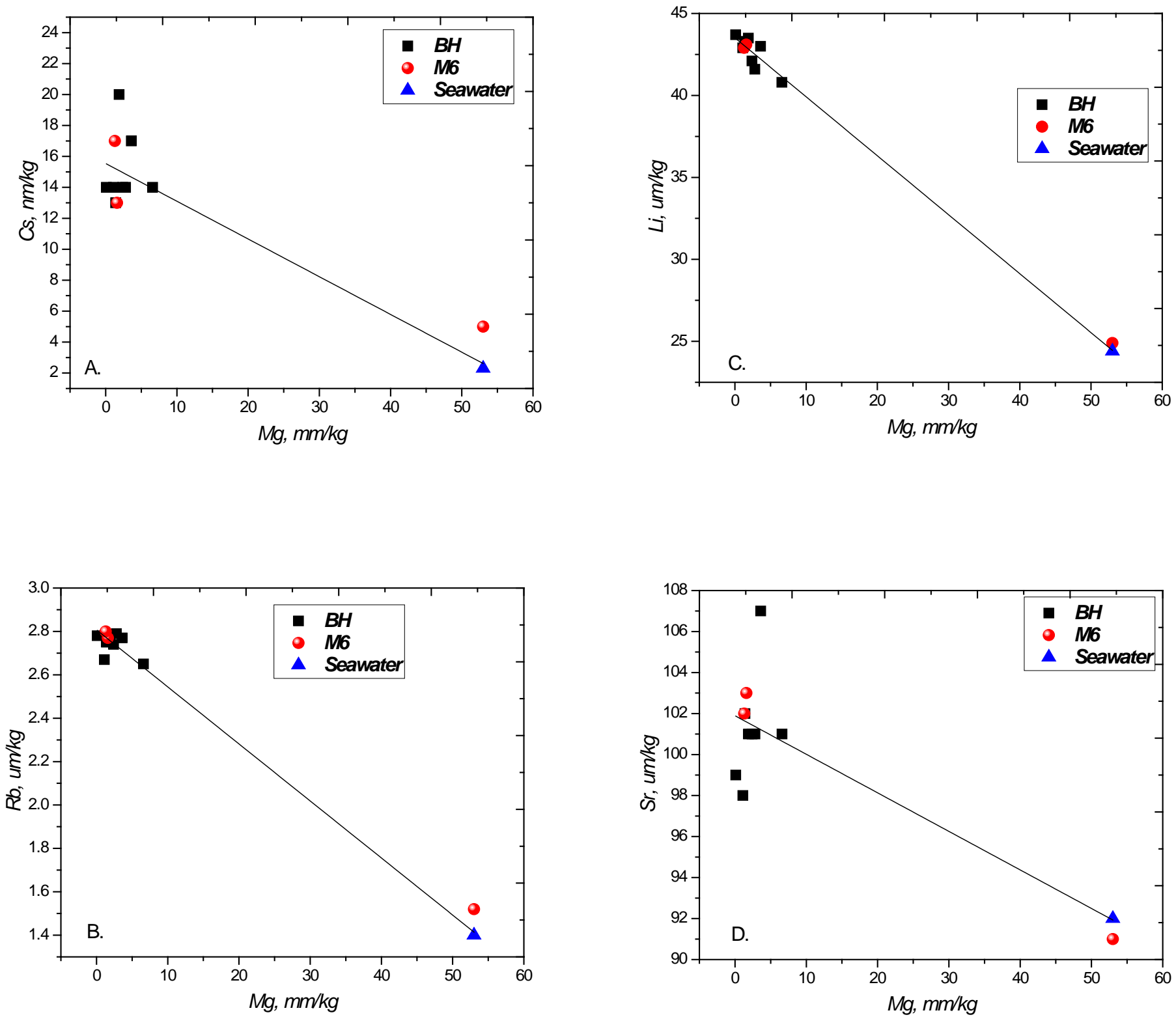
Figure 6

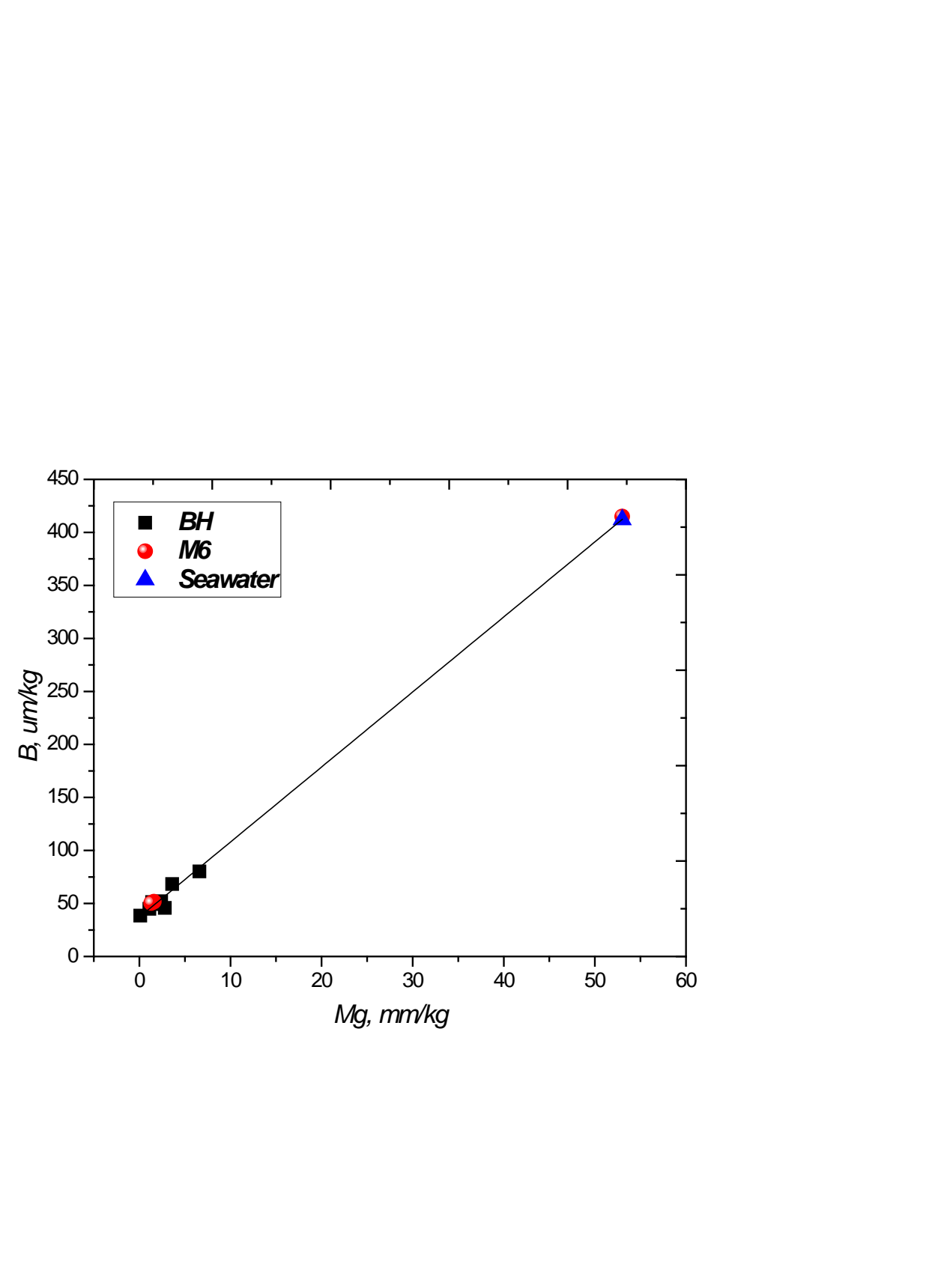

$\mathrm{Mg}, \mathrm{mm} / \mathrm{kg}$

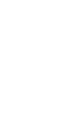

\footnotetext{
Fig. 6
}

-

政

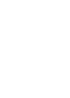

(20)

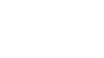

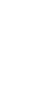

(n)

(n)
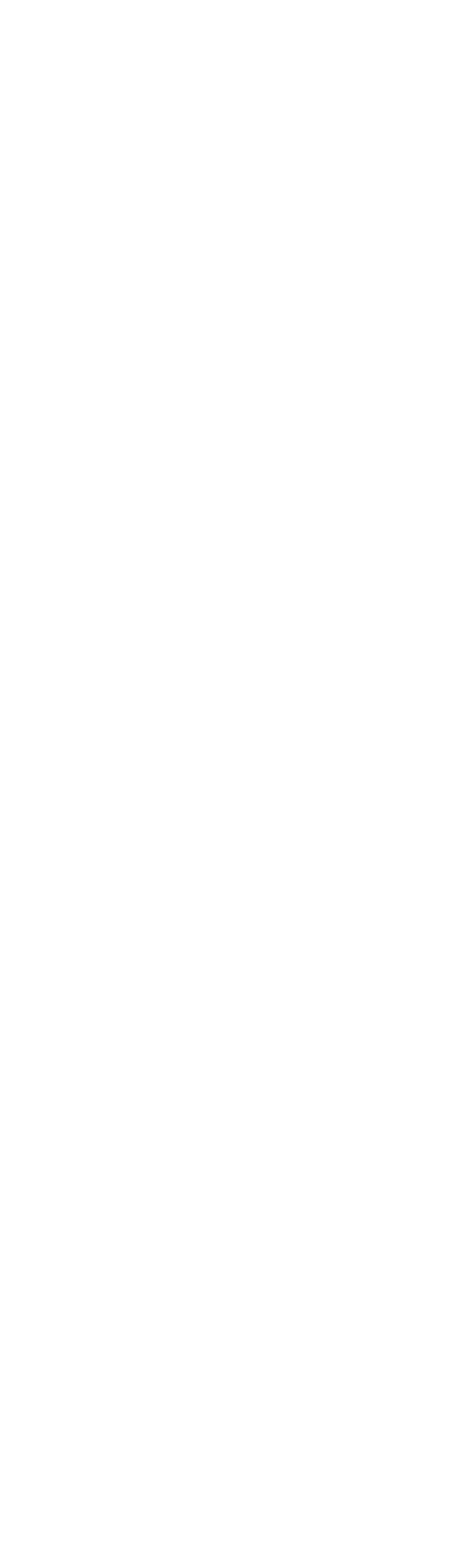

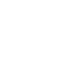

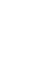

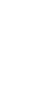

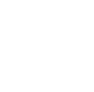
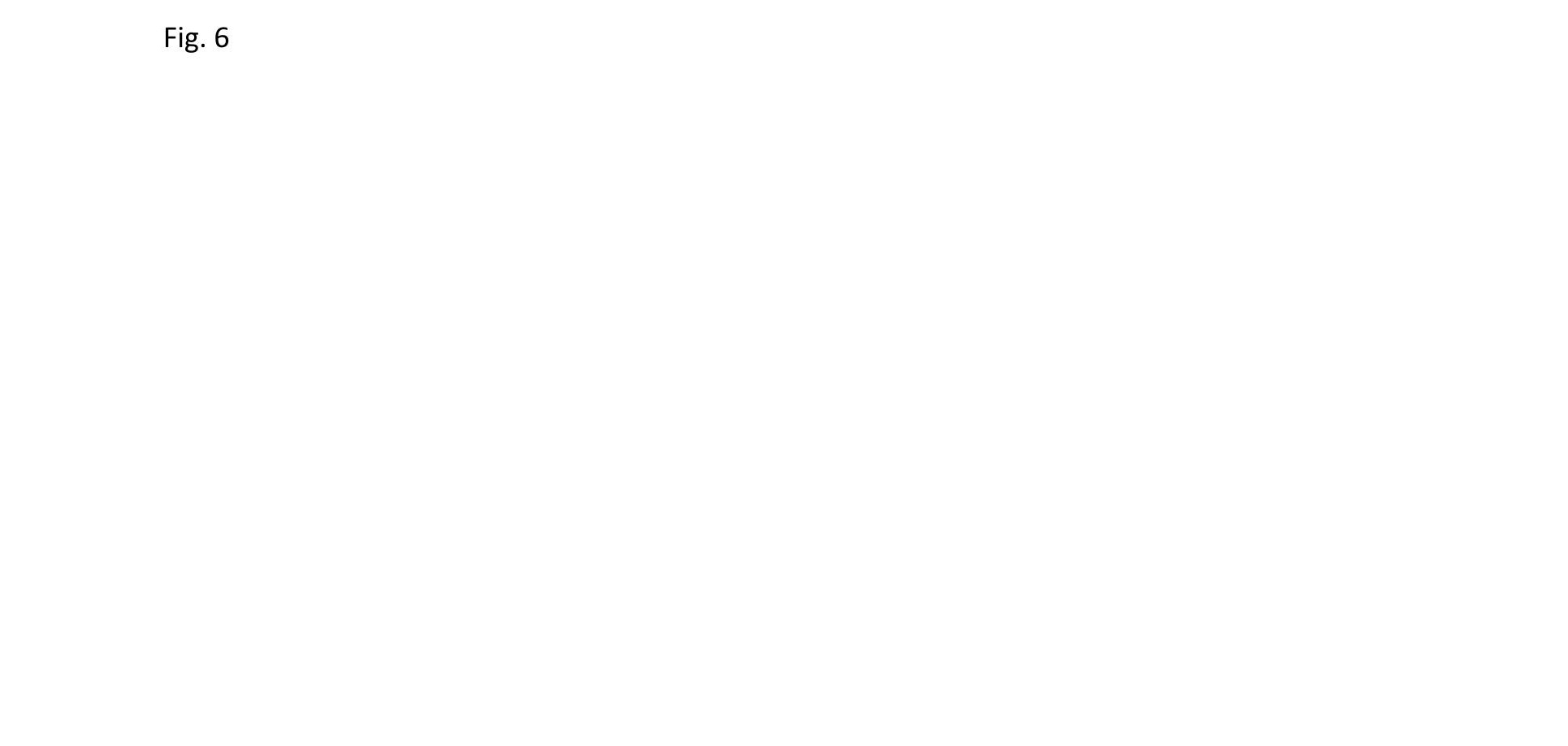
Figure 7

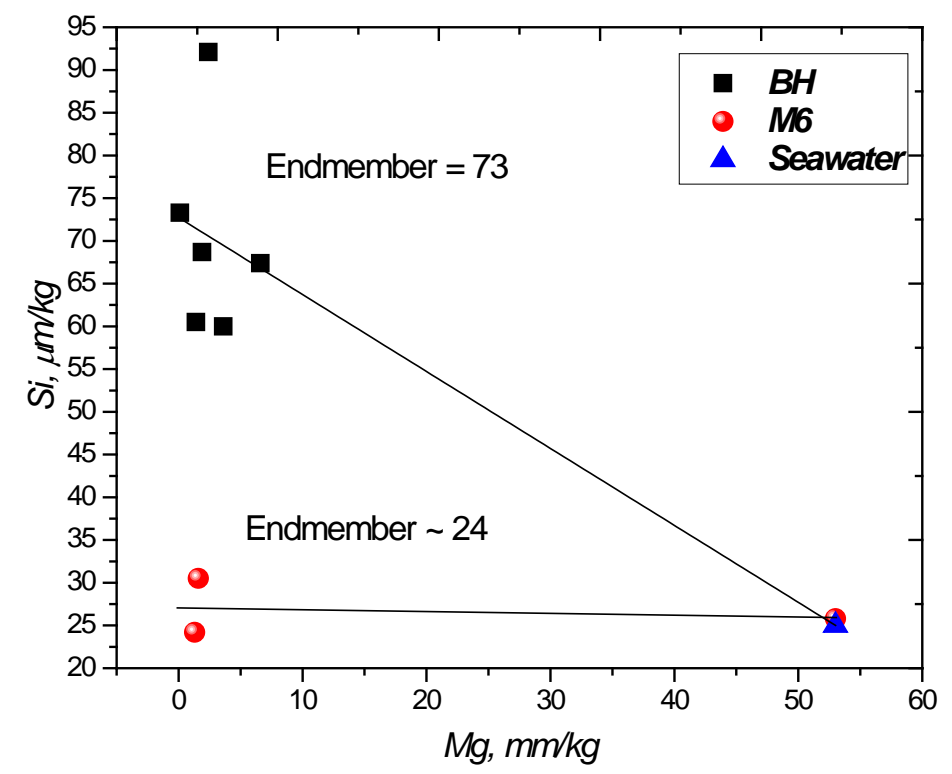

Fig. 7. 
Figure 8
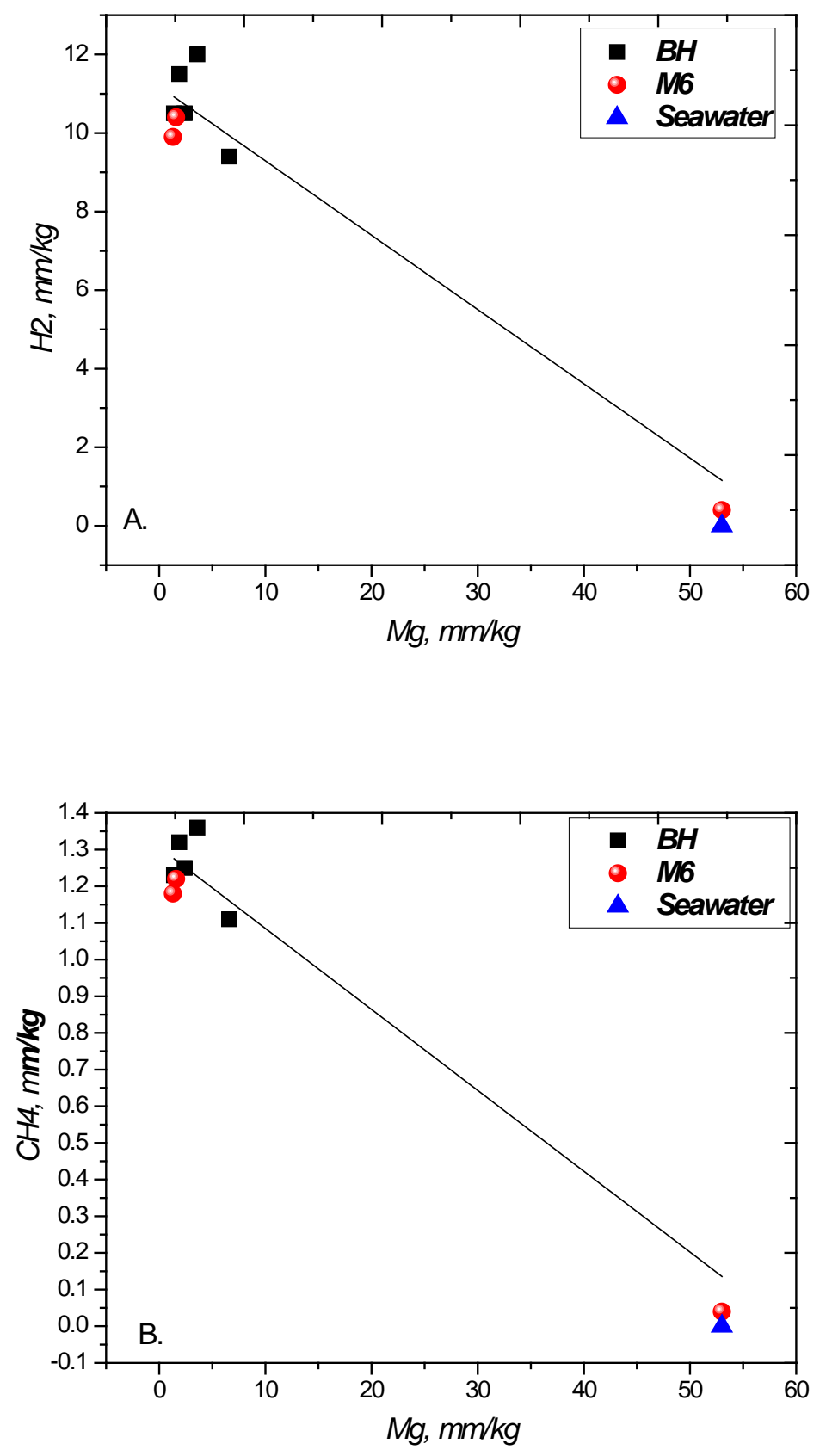

Fig. 8. 


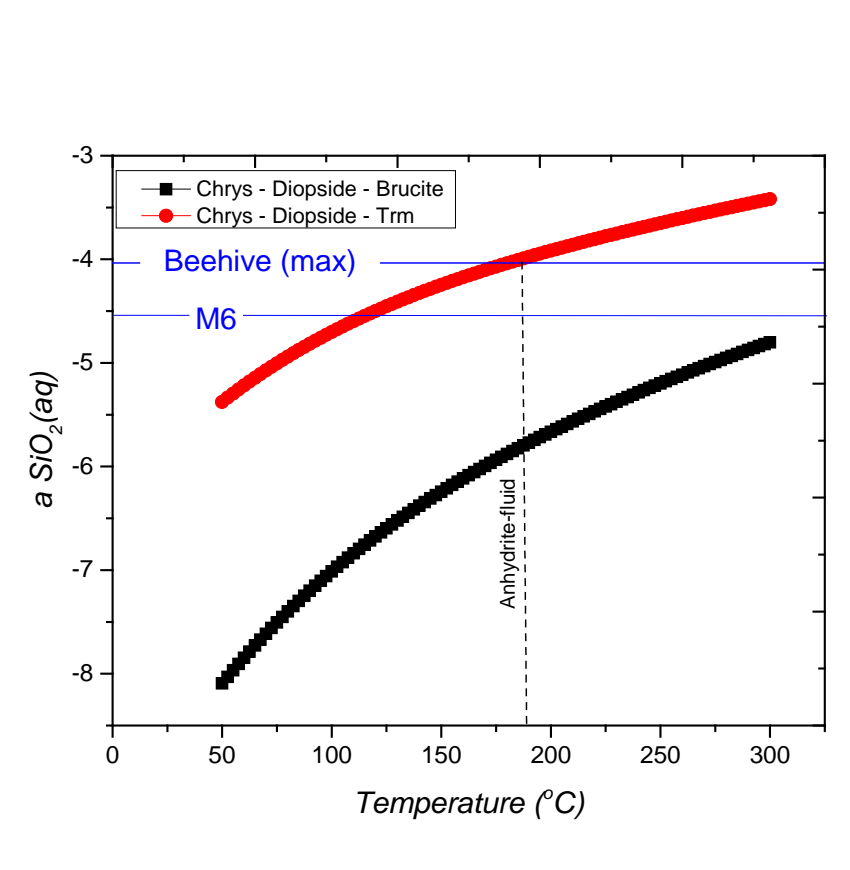

Figure 9

.

Temperature $\left({ }^{\circ} \mathrm{C}\right)$

\section{Fig. 9.}

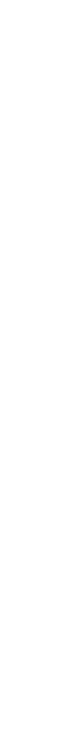

(

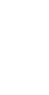

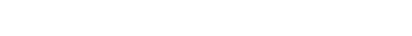

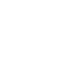
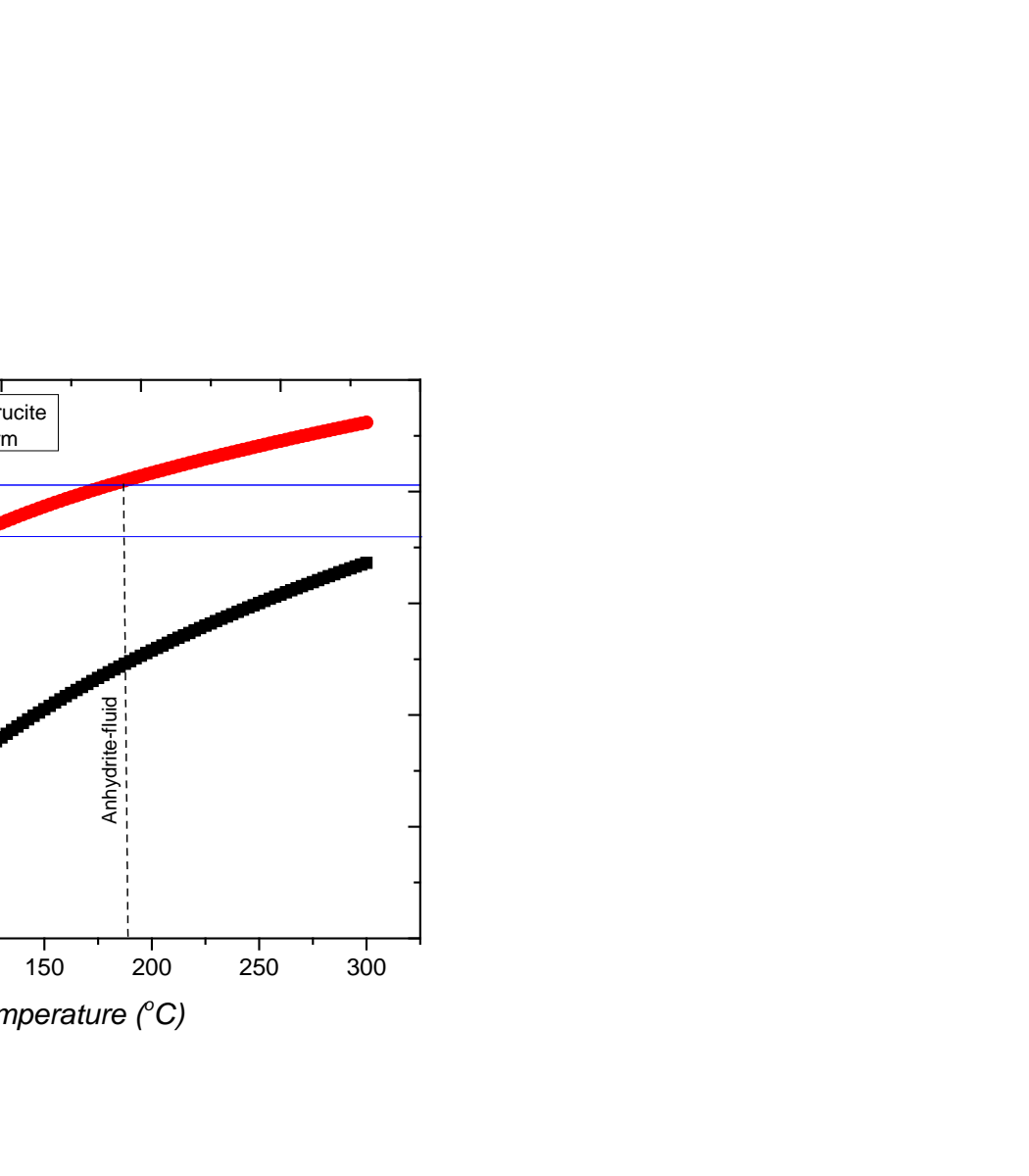$$
\text { (1) }
$$ 
Figure 10

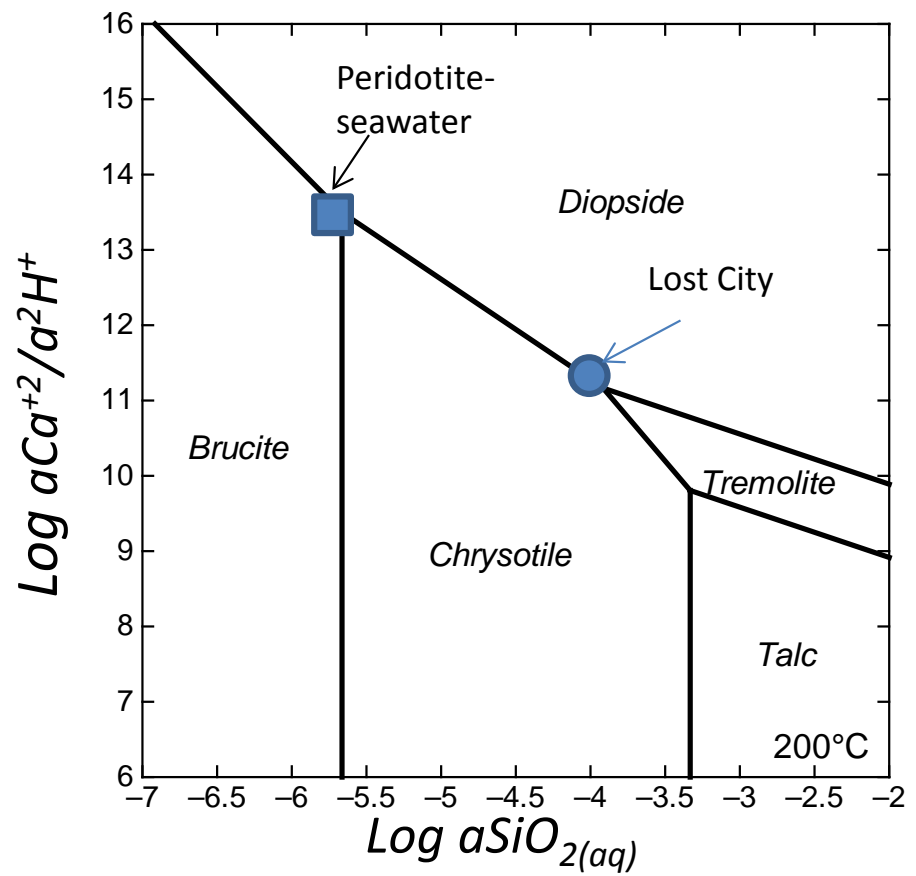

Fig. 10. 


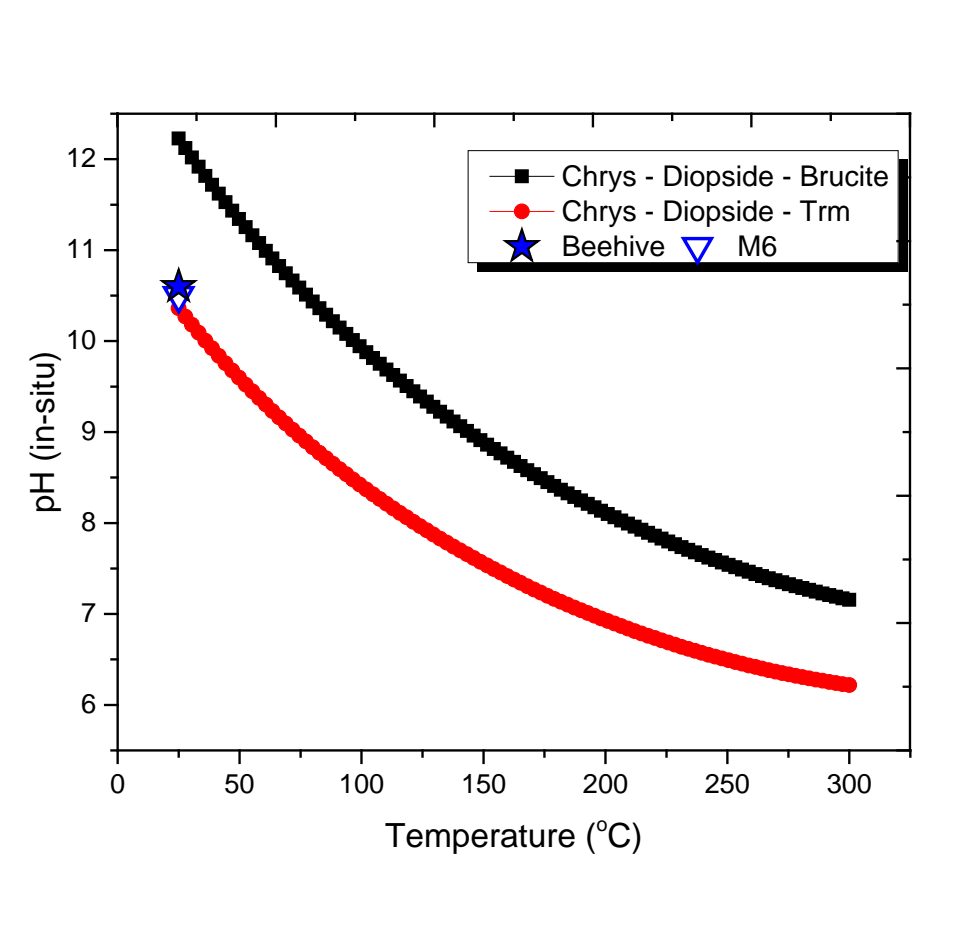

Fig.11.

Figure 11 Fig. 11.

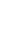
.

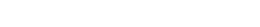

(

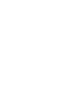
( (n)

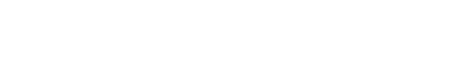
-

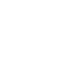
-

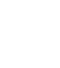

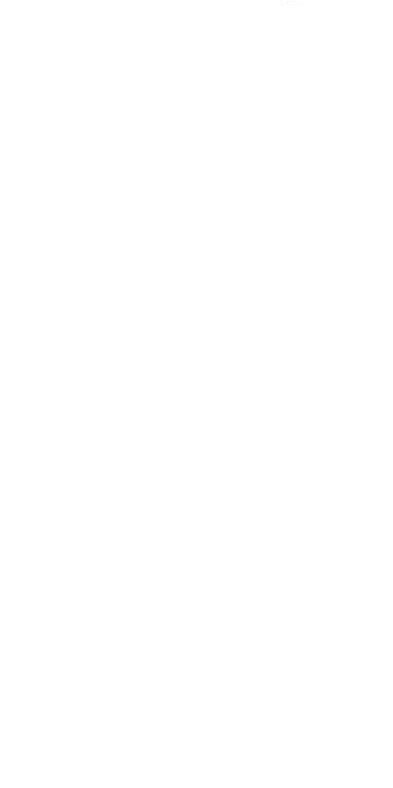



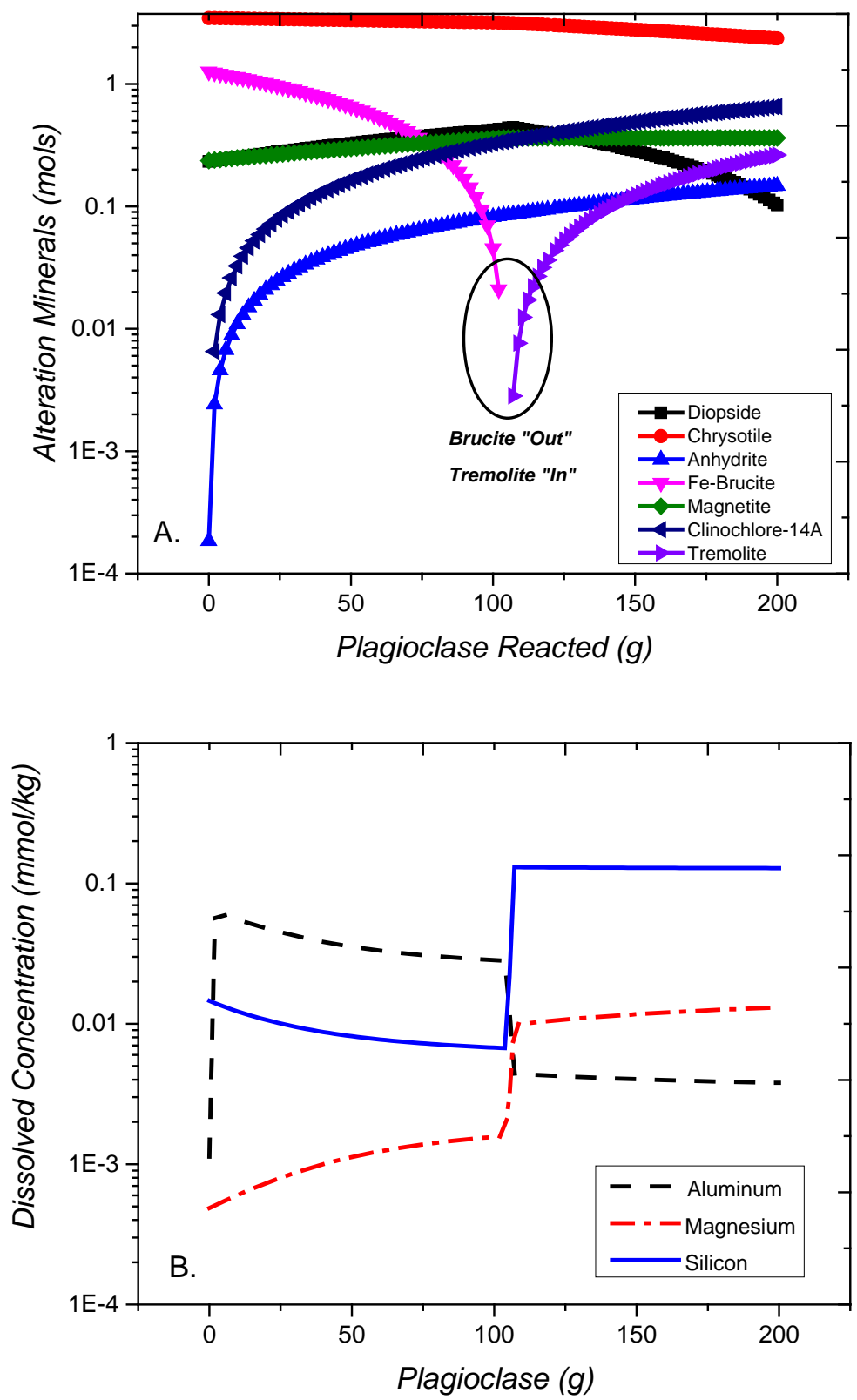

Fig. 12. 

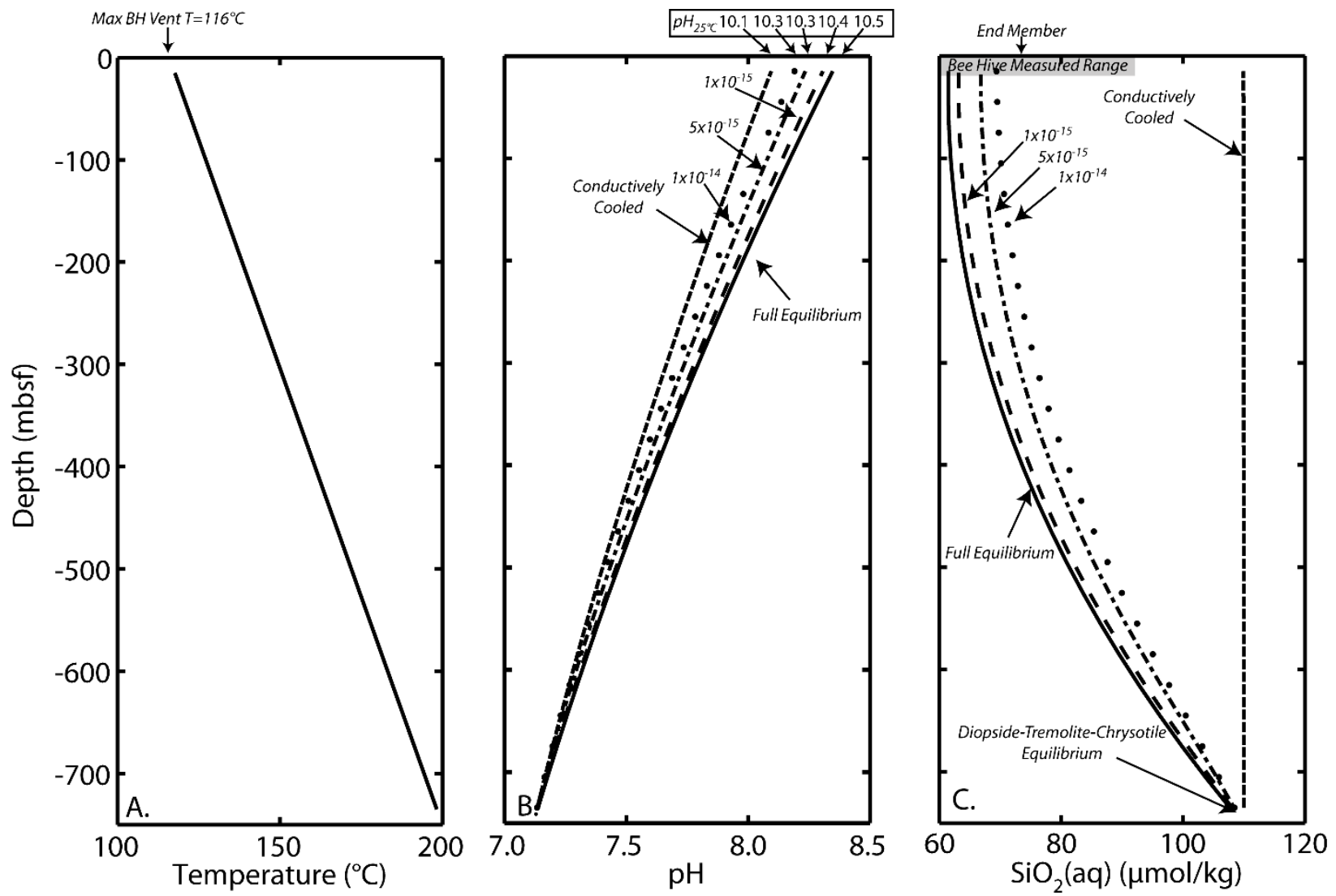

Fig. 13. 